Research Article

\title{
Combustion Turbulence Flow in the Advanced Vortex Combustor with Built-In Obstacles
}

\author{
Yu Chen $(\mathbb{D}$, Zhuoxiong Zeng $\mathbb{D}$, and Haoyuan Wang $(\mathbb{D}$ \\ College of Energy and Mechanical Engineering, Shanghai University of Electric Power, Shanghai 200090, China \\ Correspondence should be addressed to Zhuoxiong Zeng; zengzhx@163.com
}

Received 23 May 2021; Revised 2 July 2021; Accepted 7 August 2021; Published 2 September 2021

Academic Editor: Jun-Wei Li

Copyright (c) $2021 \mathrm{Yu}$ Chen et al. This is an open access article distributed under the Creative Commons Attribution License, which permits unrestricted use, distribution, and reproduction in any medium, provided the original work is properly cited.

To obtain the advanced vortex combustor (AVC) and its optimal structure parameters in light of built-in obstacles, numerical simulation was performed. This research shows that inclined struts have optimal structural parameters with inclination angle $\alpha=30^{\circ}$ and blocking ratio $\mathrm{BR}=12 \%$, while guide vane and its optimal structural parameter have three layers, which are $a / B=0.1, b / h=0.4$, and $c / L=0.2$, respectively; blunt body has the biggest height of $H_{1} / B_{1}=2 / 3$. According to these statistics, the research studies how inlet factors affect turbulence flow in combustion. The research finds increases in inlet velocity and flow resistance are in positive correlation. As inlet temperature increases, the flow resistance decreases. From field synergy theory, inlet factor has different effect on the heat transfer performance.

\section{Introduction}

In light of the energy saving and emission reduction, which are requirements on modern gas turbine and aircraft engine, the model of trapped vortex combustor (TVC) proposed in the 1990s was adopted [1]. The model is simple in structure, small in pressure loss, stable in flame, and high efficient in combustion. So, it has been paid attention widely [2-7]. Advanced vortex combustor is a representative TVC with double blunt proposed by Ramgen Company [8].

An advanced vortex combustor at different conditions was tested [8], and within a variety of conditions in operation, marked acoustic dynamic stability is described by the improved AVC design. This means the research method used by the author is significant than the usual one. A study on AVC flow features based on experiment and computation methods was carried out [9], and the study designs an annular-channel-based and annular-AVC-model-based burning hydrogen. Then, a study conducted through numerical simulation is done for understanding annular AVC model and its features. Next, AVCs with different combustion flows are studied $[10,11]$; the study shows that vortex-generator- based AVC performs better than those pure AVC. Based on this, it studies how parameters of injections affect AVC performances. A modified advanced vortex combustor is designed to overcome the incomplete combustion of fuel. The proposed advanced vortex combustor is characterized by inclined struts and guide vanes. This modified advanced vortex combustor is well suited to working under lean-fuel conditions [12]. The four-channel annular inlet advanced vortex combustor (AVC) can act as a flame channel when the lean oil is burning. With the introduction of the guide vane, a stable double vortex structure is formed in the cavity, and the combustion efficiency is greatly improved [13]. The guide vane and inclined strut TVC were combined $[14,15]$ and perform better than those TVC without these devices.

In light of AVC structure and former academic studies [15], this research proposes an advanced vortex combustor with built-in obstacles (including guide vane and inclined struts as well as blunt body). As built-in obstacle structural parameters and combustor are in close correlation, the vortex structures and flow characteristics of AVC vary and change along with built-in obstacles' structural parameters. So, AVC and its structural parameter are studied to explore 

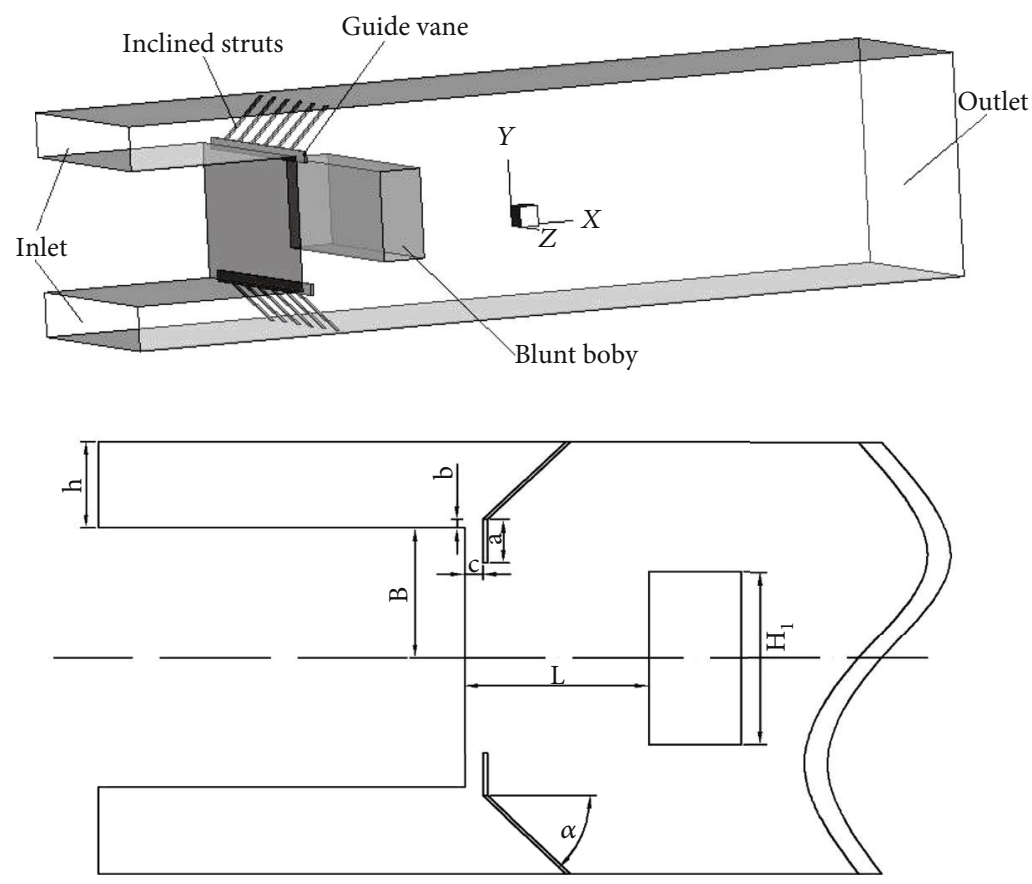

FIgURE 1: AVC geometric model with built-in obstacles.

optimal parameters of the structure and thus promote AVC performance. Then, in light of the optimal structure, it studies how inlet conditions affect AVC combustion flow.

\section{Geometric Model}

Figure 1 shows AVC geometric model with built-in obstacles (including guide vane, inclined struts, and blunt body). Coordinates originate from combustor center. Combustor is square, and it is a channel with three directions of $(X, Y$, and $Z$ ) and size in $400 \mathrm{~mm} \times 100 \mathrm{~mm} \times 100 \mathrm{~mm}$; the size of each inlet section is $20 \mathrm{~mm} \times 100 \mathrm{~mm}$; the blunt body has the size $20 \mathrm{~mm} \times 40 \mathrm{~mm} \times 100 \mathrm{~mm}$. Six inclined struts are arranged symmetrically along section $Z=0 \mathrm{~mm}$, the distance every two struts is $12 \mathrm{~mm}$, and the width of each inclined strut is $1 \mathrm{~mm} . L=40 \mathrm{~mm}, B=30 \mathrm{~mm}$, and $h=20 \mathrm{~mm} . Z=0 \mathrm{~mm}$ is the combustor center cross section between the inclined struts. $Z=7 \mathrm{~mm}$ is the middle cross section through one inclined strut. The definitions and values of structure parameters are shown in Tables 1 and 2, where BR (the blocking ratio) is the ratio of the projected area of the inclined struts on $Y Z$ plane to the projected area of the guide vane on $Y Z$ plane.

\section{Numerical Model and Boundary Conditions}

Realizable $k-\varepsilon$ model [16] and the eddy-dissipation model [17] are adopted. Pressure and velocity coupling are simple in methodology [18], and the scheme of central and upwind differences with second-order is adopted to term diffusion and convective with pertinence. The combustion model has finite rate. The combustion reaction equation uses methane-air one-step reaction. For gaining solutions with grid independence, computation meshed with 1914527 mixed (hybrid) cells is used.
TABle 1: Definition of structure parameters.

\begin{tabular}{lc}
\hline Parameter & Definition \\
\hline$h(\mathrm{~mm})$ & Inlet section height \\
$a(\mathrm{~mm})$ & Inlet-cavity-length of guide vane \\
$b(\mathrm{~mm})$ & Gap guide vane and cavity leading edge \\
$c(\mathrm{~mm})$ & Gap between guide vane and cavity wall \\
$L(\mathrm{~mm})$ & Gap between blunt body and cavity wall \\
$B(\mathrm{~mm})$ & Half height of the cavity wall \\
$H_{1}(\mathrm{~mm})$ & Blunt body height \\
$\alpha\left({ }^{\circ}\right)$ & Inclination angle \\
BR $(\%)$ & The blocking ratio \\
\hline
\end{tabular}

TABLE 2: Value of structure parameters.

\begin{tabular}{lc}
\hline Parameter & Value \\
\hline$\alpha$ & $30^{\circ}, 45^{\circ}, 60^{\circ}, 75^{\circ}, 105^{\circ}$ \\
BR $(\%)$ & $12,24,36,48,60$ \\
$a / B$ & $0.1,0.2,0.3,0.4,0.5,0.6$ \\
$b / h$ & $0.1,0.2,0.3,0.4$ \\
$c / L$ & $0.1,0.2,0.3,0.4,0.5$ \\
$H_{1} / B_{1}$ & $1 / 3,1 / 2,2 / 3,5 / 6$ \\
$B=0.5 B_{1}(\mathrm{~mm})$ & 30 \\
\hline
\end{tabular}

Mainstream inlet velocity is $50 \mathrm{~m} / \mathrm{s}$, inlet temperature is $300 \mathrm{~K}$, and equivalence ratio is 0.6 . Gaseous methane fuel $(\mathrm{CH} 4)$ gains its inlet premix, and its pressure at outlet is 1 atmospheric pressure. For convection combustor wall boundary, heat transfer coefficient is $30 \mathrm{~W} /\left(\mathrm{m}^{2} \cdot \mathrm{K}\right)$. Coupled 


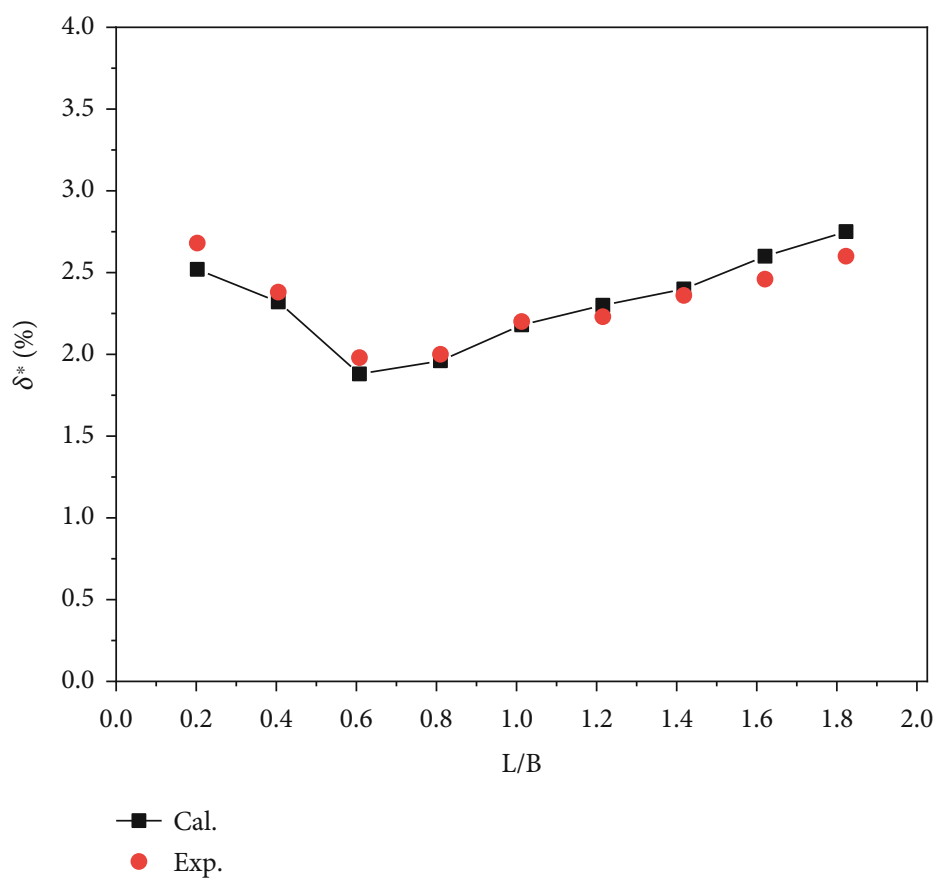

(a) Total pressure loss under different $L / B$

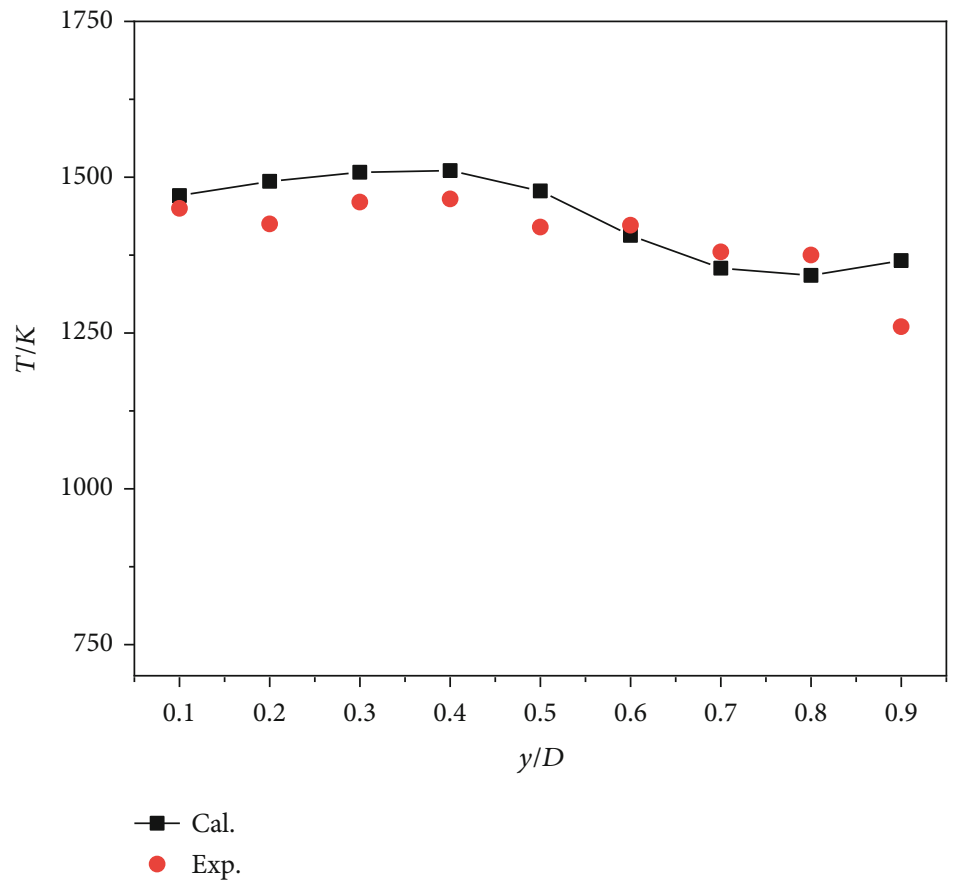

(b) Outlet radial temperature distribution

FIgURE 2: Comparison between simulation and experiment.

thermal boundary combines with blunt body, guide vane, and inclined struts. No-slip condition is for the wall.

\section{Numerical Results and Analysis}

The total pressure loss coefficient obtained by simulation and experiment [19] are compared for a height ratio of 0.7 between the rear blunt body and the front blunt body is shown in Figure 2(a). Outlet radial temperature distribution gained by simulation and experiment [15] are compared for a single cavity with guide vane and 4 inclined struts is shown in Figure 2(b). $D$ is the distance from the upper wall of the blunt body to the combustor upper wall. In most regions, numerical results and experiment are in positive correlation, and this indicates the credibility of numerical model and conditions for boundary adopted in the research. 


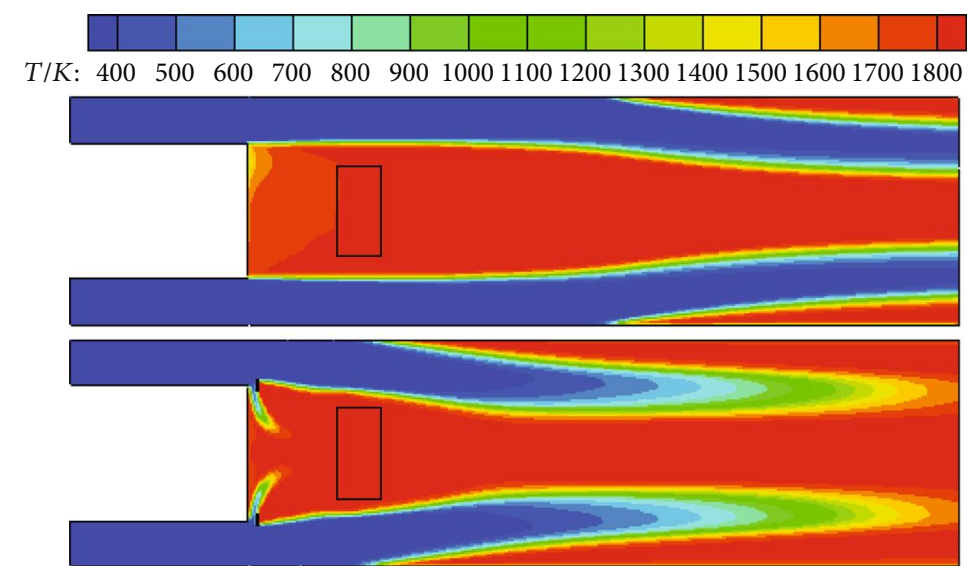

(a) Temperature distribution
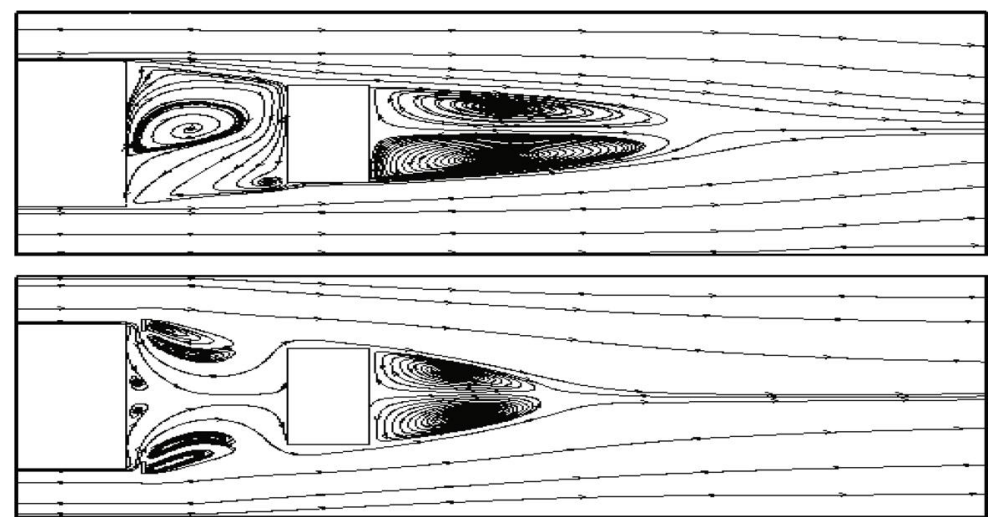

(b) Velocity distribution

FIgURE 3: Velocity and temperature distribution with or without the guide vane and inclined struts.

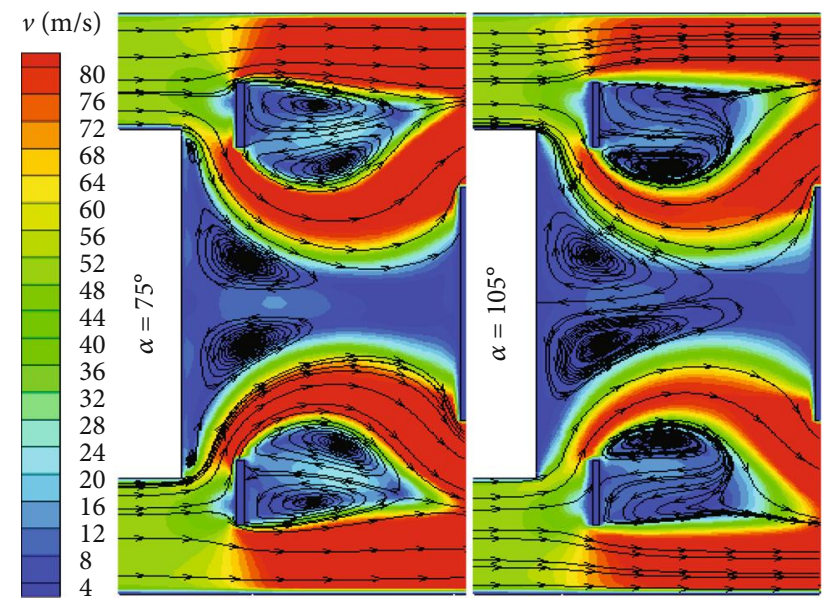

(a)

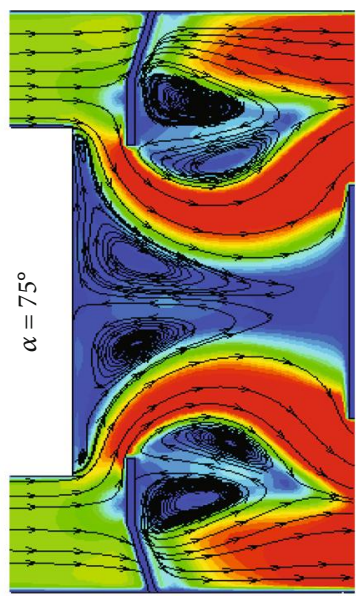

(b)

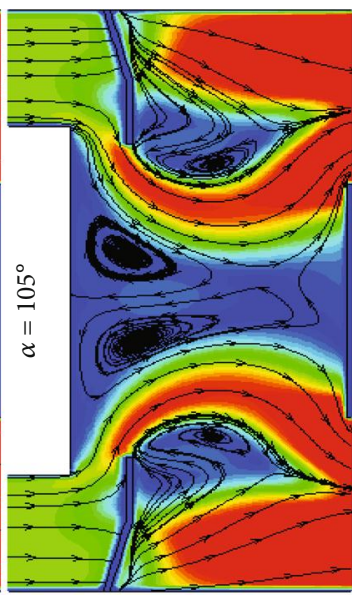

Figure 4: Velocity distribution under different struts inclining direction.

4.1. Effect of Structure Parameters of the Built-In Obstacles on the AVC Combustion Flow Characteristics. Figure 3 shows the temperature and velocity distribution with the guide vane and inclined struts or not. At section $Z=0 \mathrm{~mm}$, when the guide vane and inclined struts do not exist, it cannot form a stable vortex inside the cavity [20], temperature of the cavity is obviously lower, combustion is not uniform, and outlet temperature gradient is larger; combustion efficiency is about $64 \%$. When there are guide vane and inclined struts, two sets of stable double vortex structures can be formed to be good to stabilize combustion, with combustion efficiency exceeds $98 \%$. 

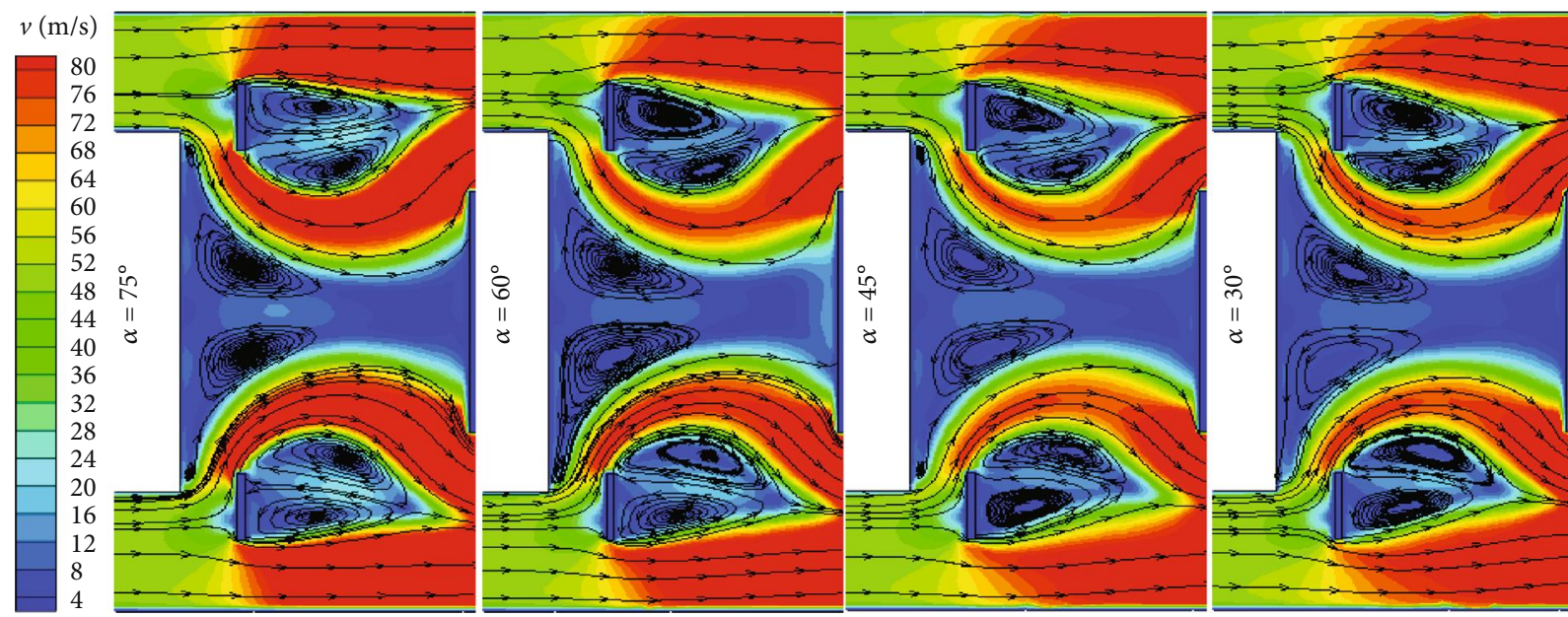

(a) $Z=0 \mathrm{~mm}$
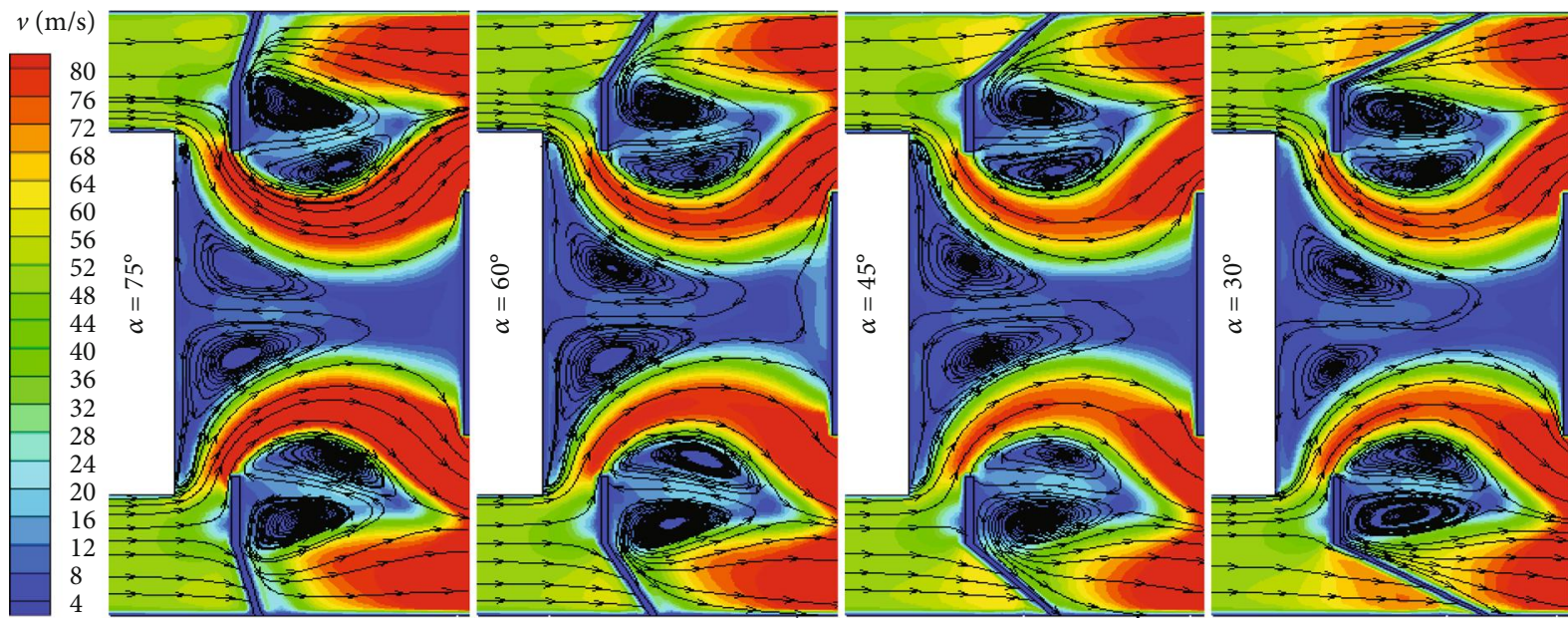

(b) $Z=7 \mathrm{~mm}$

Figure 5: Velocity distribution in the cavity under different $\alpha$.

4.1.1. Effect of Inclination Angle on the Characteristics of $A V C$. Figure 4 shows the velocity distribution for struts inclining downstream and upstream. When the struts incline upstream (inclination angle $\alpha$ is greater than $90^{\circ}$ ), it is impossible to form the stable double vortices behind the guide vane, and the ignition stability is poor, so this case should not be adopted.

Figure 5 shows velocity distributed at cavity with different $\alpha$. When $\alpha$ decreases, there is no obvious variation for double vortices, and center of the inner vortex gets close to cavity center, and velocity of gas in the cavity decreases slightly. In addition, with the decrease of $\alpha$, the velocity of the gas through the struts' gap increases (see Figure 5(a)), and along the flow direction, the gas velocity on both sides of the inclined struts also increases (see Figure 5(b)), which can enhance the mixing of unburned gas with combustion products in the cavity. It can be found that the velocity field by present model is different with that without blunt body [15] and origin AVC without the guide vane and inclined struts. The present model has three sets of double vortices, which makes mix and combustion easier, the model [15] has one vortex in the single cavity, and origin AVC has two sets of double vortices in the cavity formed by two blunts.

The influence of different inclination angle on combustion performance and the flow field structure includes total pressure loss and combustion efficiency [21].

$$
\text { Total pressure loss } \delta^{*}=\frac{P_{1}^{*}-P_{2}^{*}}{P_{1}^{*}}
$$

where $P_{1}{ }^{*}$ is the total pressure of inlet and $P_{2}{ }^{*}$ is the total pressure of outlet.

$$
\text { Combustion efficiency } \eta=\frac{M_{\text {fuel,in }}-M_{\text {fuel,out }}}{M_{\text {fuel,in }}} \text {, }
$$

where $M_{\text {fuel,in }}$ is the mass fraction of combustor inlet fuel and $M_{\text {fuel,out }}$ is the mass fraction of combustor outlet fuel.

As can be seen from Figure 6, inclination angle $\alpha$ and combustion efficiency are not that relevant, and combustion efficiency exceeds $99 \%$. In the range of $30^{\circ} \sim 75^{\circ}$, with the decrease of angle $\alpha$, total pressure loss decreases gradually 


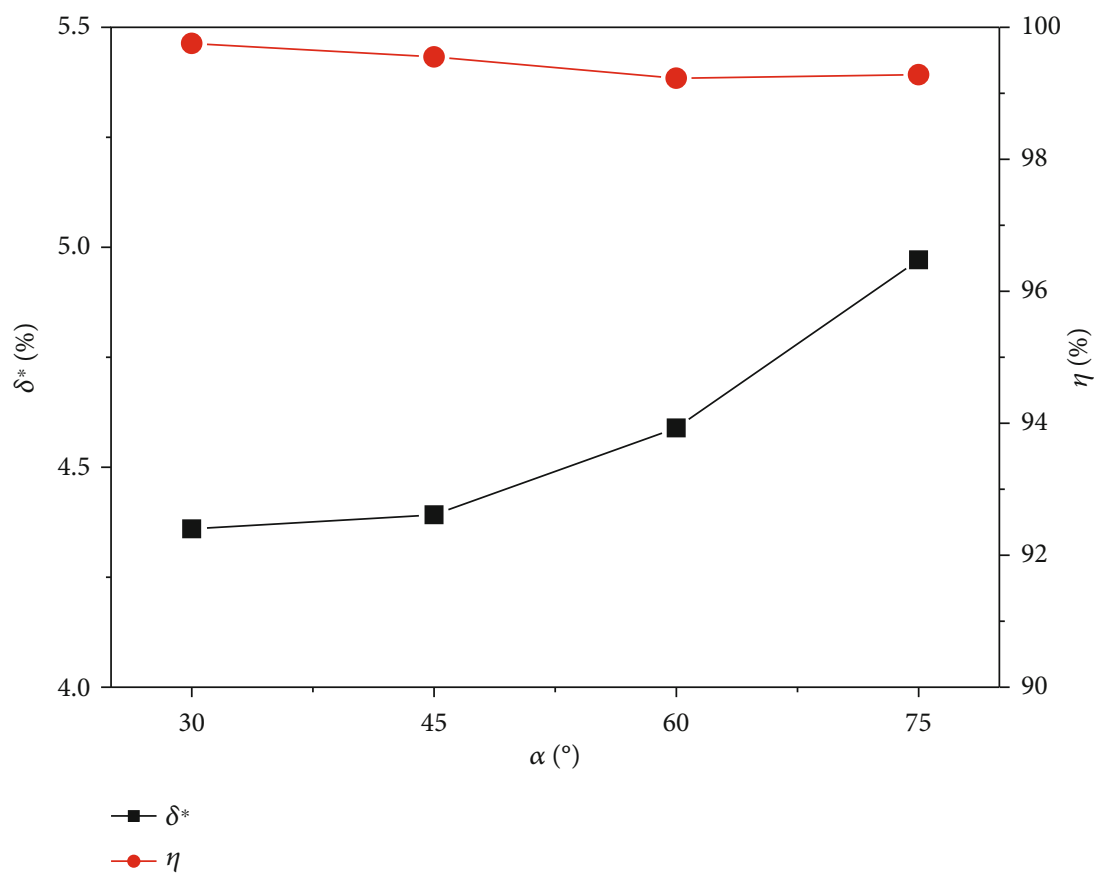

Figure 6: Total pressure loss and combustion efficiency under different $\alpha$.

due to the awakened flow in obstruction, and mainstream flow resistance decreases.

\subsubsection{Effect of the Blocking Ratio (BR) on the Characteristics} of $A V C$. Figure 7 shows cavity velocity distributed with different BR. Within the cavity, when $Z$ is $0 \mathrm{~mm}$, as BR increases, double vortices of it decrease, and outer vortex region and length both decrease obviously, but the change of inner vortex is small; the double vortex center position gradually closes to the rear wall of the guide vane. The velocity of the fuel-air mixture into the cavity and the mainstream outside the guide vane increases. At section $Z=7 \mathrm{~mm}$, with the increase of $\mathrm{BR}$, the outer vortex is broken up, the area of inner vortex decreases, the velocity of the fuel-air mixture into the cavity also increases, and the velocity of combustion product behind the inclined struts increases.

Figure 8 shows the total pressure loss and combustion efficiency under different BR. When BR increases, total pressure loss increases on condition that the area of the inclined struts and the hindrance to the mainstream increase obviously. On the other hand, the flow velocity of mixture through the guide vane and inclined struts increases, which results in the increase of gas flow resistance. However, combustion efficiency is basically unchanged when BR varies, which is due to the fact that inclined struts under different $\mathrm{BR}$ can enhance the mixing and make the combustion full.

4.1.3. Effect of $a / B$ on the Characteristics of $A V C$. The velocity distribution in the cavity at section $Z=0 \mathrm{~mm}$ under different $a / B$ is shown in Figure 9. Two sets of double vortex structures can be formed under different $a / B$, the inner vortex plays the role of ignition and combustion stabilization, and the outer vortex structures can be formed behind the guide vane and inclined struts. On the one hand, the outer vortex can protect the inner vortex; on the other hand, the outer vortex is helpful to strengthening the mainstream mixture and cavity gas.

At the $a / B=0.1$, gas from guide vane to cavity into the cavity forms a set of small vortices near the cavity front wall. As $a / B$ increases, small vortex diminishes, outer vortex area increases gradually, there is no significant change for the size of the inner vortex when $a / B=0.1,0.2$, and 0.3 , the inner vortex area increases when $a / B$ continues to increase, and its vortex center moves downstream; this is because the area of the outer vortex increases, and the outer vortex squeezes the space occupied by the inner vortex, which is not enough to form a fully developed inner vortex.

Figure 10 indicates how different $a / B$ affects on total pressure loss and combustion efficiency $(a / B=0$ indicates there are no guide vane and inclined struts). When $a / B$ increases from 0.1 to 0.6 , the change of total pressure loss is less than $0.1 \%$, which indicates that total pressure loss is very little affected by $a / B$. In comparison to AVC, with no guide vane nor inclined struts, total pressure loss increases obviously, and for that, the two elements have a strong hindrance to the flow and increase the flow resistance of the mainstream.

From Figure 10, different $a / B$ and its efficiency in combustion exceed $98 \%$, which is much higher than that without the guide vane and inclined struts. At the condition of $a / B>0.4$, efficiency in combustion decreases slightly due to the increase of gas velocity in the cavity which decreases residence time, and the insufficient mixing of gas leads to insufficient combustion.

4.1.4. Effect of $b / h$ on the Characteristics of $A V C$. Distribution of velocity in the cavity at section $Z=0 \mathrm{~mm}$ is shown in Figure 11. A stable double vortex structure is formed 

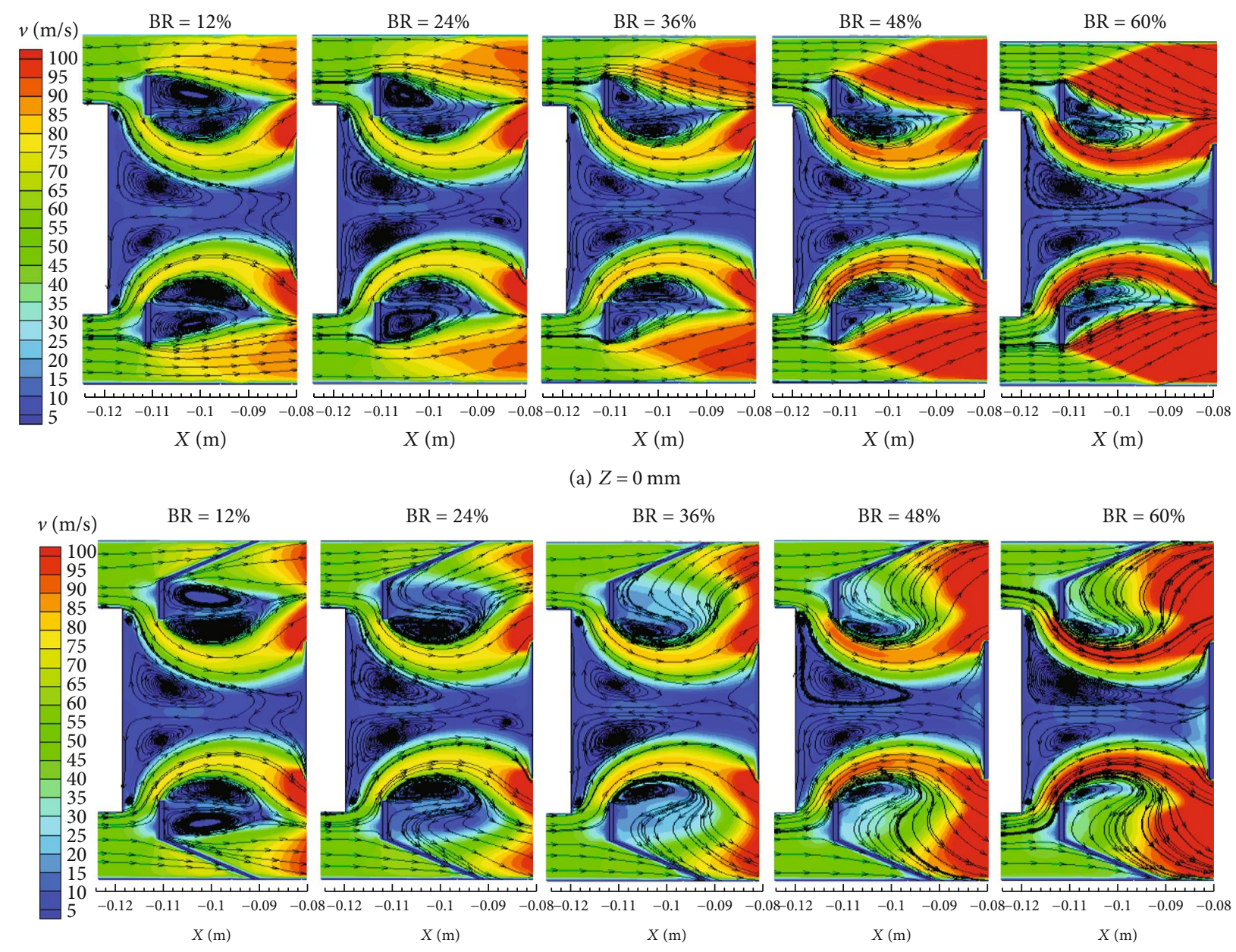

(a) $Z=0 \mathrm{~mm}$

$$
\mathrm{BR}=36 \%
$$
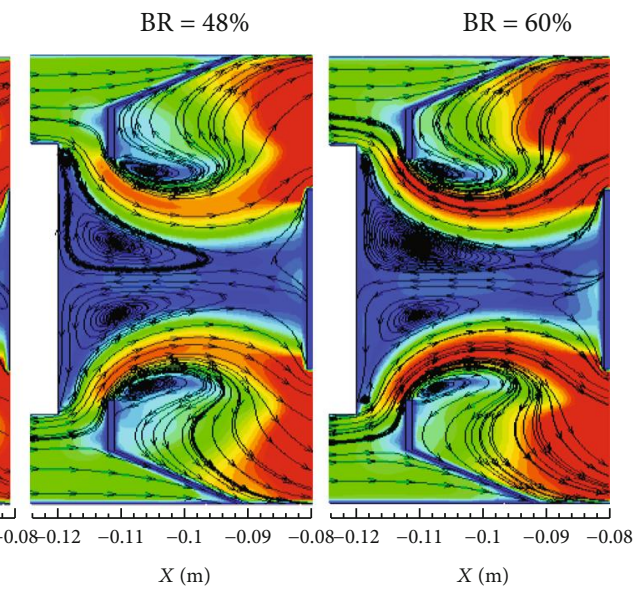

(b) $Z=7 \mathrm{~mm}$

FIgURe 7: Velocity distribution under different BR.

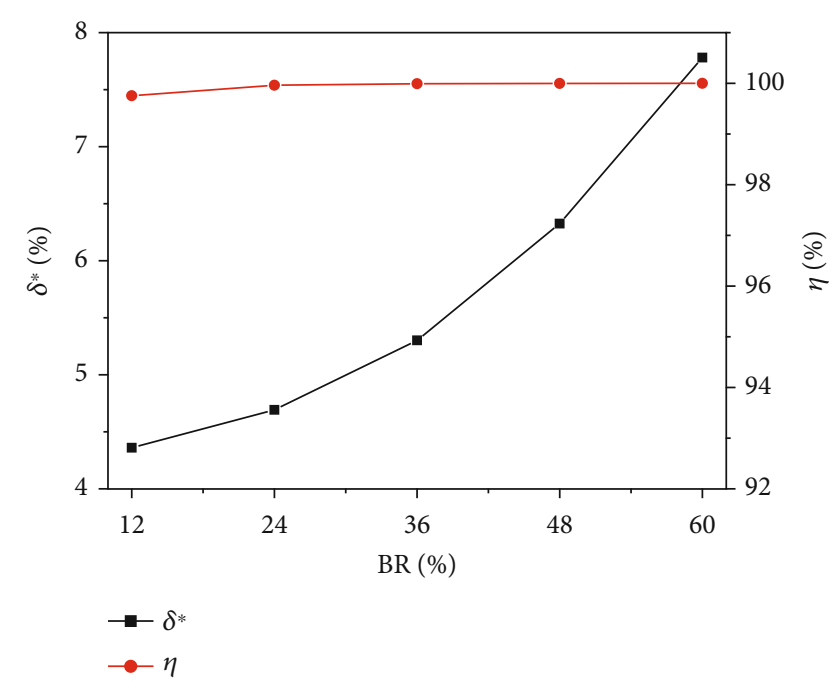

FIGURE 8: Total pressure loss and combustion efficiency under different BR. under different $b / h$. When $b / h$ increases, the double vortex region increases gradually. This is beneficial to providing a stable ignition source and promoting gas mixing. The increase of $b / h$ increases the fuel-air mixture, which enters to cavity by the guide vane and inclined struts, and the gas velocity in the cavity increases obviously. At the same time, narrowness of the inlet main channel contributes to the larger flow velocity outside the guide vane, and this is beneficial to enhance transfer of heat and mass between mainstream and gas and thus improves combustion performance.

Figure 12 shows the total pressure loss and combustion efficiency under different $b / h$. As $b / h$ increases, total pressure loss increases, because the larger the $b / h$, the greater the obstruction generated by guide vane on the mainstream, while flow resistance increases. At the condition of $b / h=0.1 \sim 0.2$, combustion efficiency decreases. When $b / h>0.2$, as $b / h$ increases, efficiency in combustion can be improved effectively. The increase of $b / h$ can lead more gas into the cavity, which improves gas mixture and enhances transfer of heat and mass and thus makes the combustion more complete.

4.1.5. Effect of $c / L$ on the Characteristics of AVC. Figure 13 reveals the velocity distribution at section $Z=0 \mathrm{~mm}$ under 
$v(\mathrm{~m} / \mathrm{s}) \quad 3 \quad 6 \quad 91215182124273033363942454851545760$

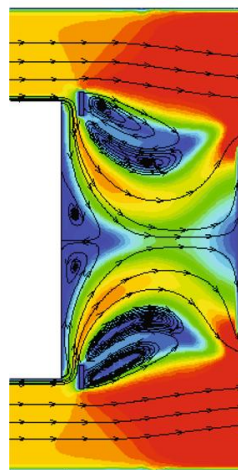

(a) $a / B=0.1$

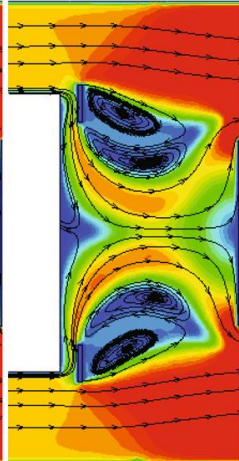

(b) $a / B=0.2$

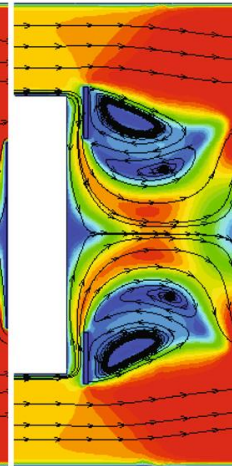

(c) $a / B=0.3$

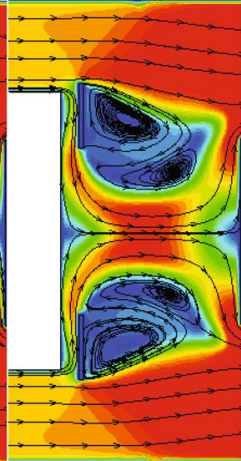

(d) $a / B=0.4$

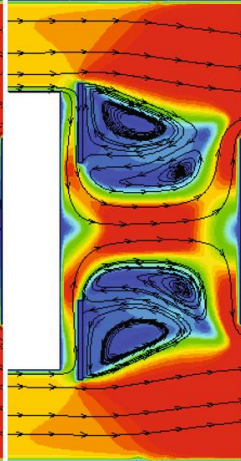

(e) $a / B=0.5$

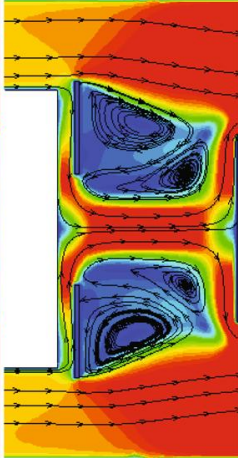

(f) $a / B=0.6$

FIgUre 9: Velocity distribution in the cavity at section $Z=0 \mathrm{~mm}$ under different $a / B$.

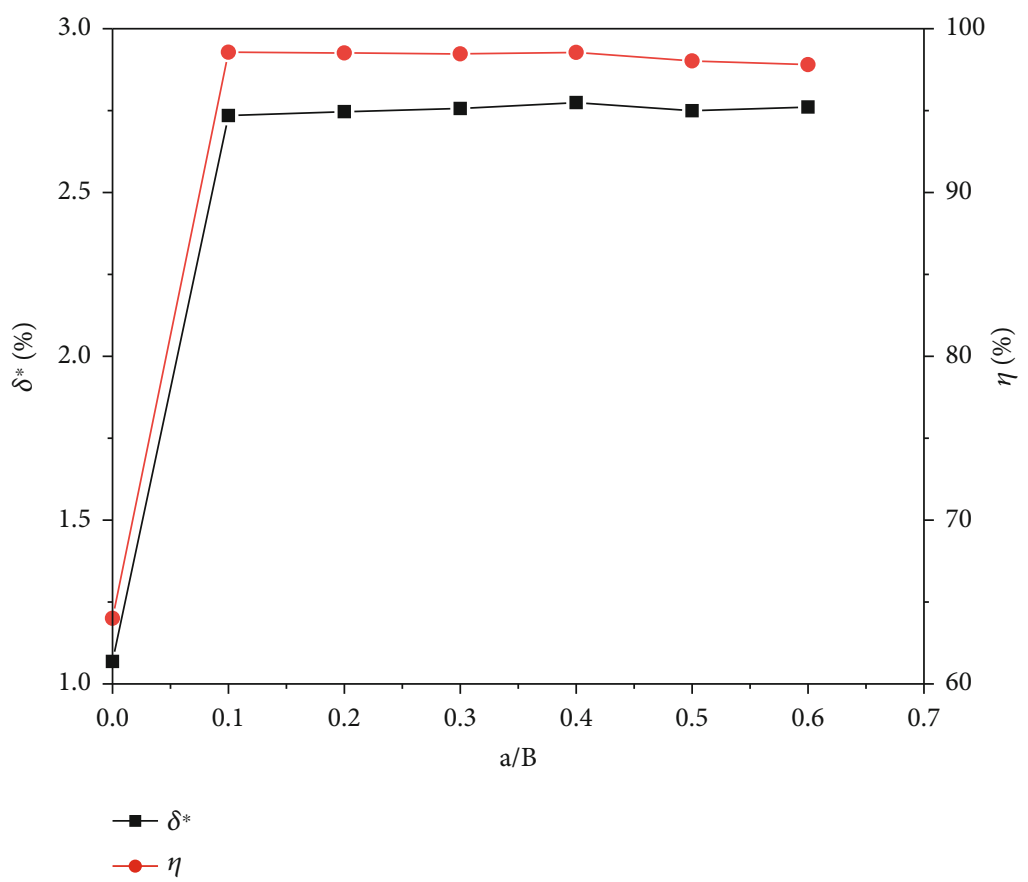

Figure 10: Total pressure loss and combustion efficiency under different $a / B$.

different $c / L$. Within the cavity, this forms a double vortex structure. When $c / L$ increases, guide vane position moves downstream step by step, the effective length of the cavity decreases, the flow in the cavity changes obviously, and the formed area of double vortices at the back of guide vane decreases gradually. There is an increase of vortex formed close to the front wall of the cavity till the whole area of the cavity is filled, and it is noninfluential to mix gas and combustion products. The gas velocity in the cavity also decreases as the guide vane moves downstream.

Figure 14 shows the change of total pressure loss and combustion efficiency under different $c / L$. Total pressure loss can be effectively reduced by increasing the $c / L$, and this is because of the increase of the distance from guide vane to front wall of the cavity; some gas enters cavity freely, but it decreases flow resistance generated from the guide vane to the mainstream. But $c / L$ has no significant effect on combustion efficiency, and combustion efficiency exceeds $99.2 \%$.

4.1.6. Effect of $H_{1} / B_{1}$ on the Characteristics of $A V C$. Flow field distribution in the combustor is shown in Figure 15. When blunt body is set, combustor flow field changes, and a backflow zone is formed behind to be helpful to further mixing gas and combustion product. However, the vortex number in the cavity does not change, the length of the double vortex structure behind the guide vane is shortened, and the area of the double vortices near the cavity front wall is increased. 


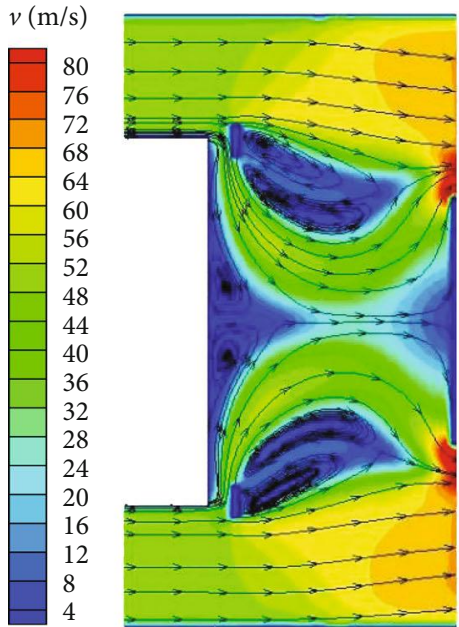

(a) $b / h=0.1$

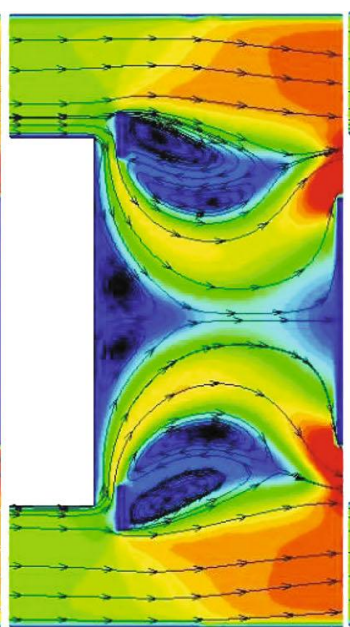

(b) $b / h=0.2$

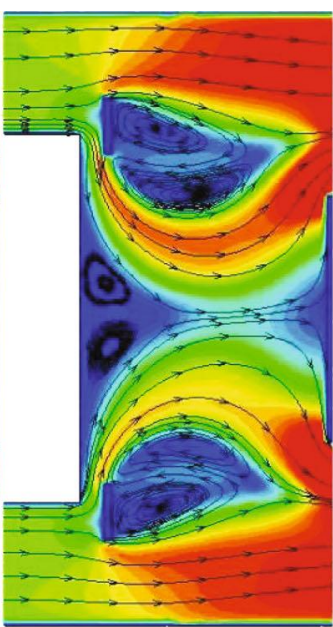

(c) $b / h=0.1$

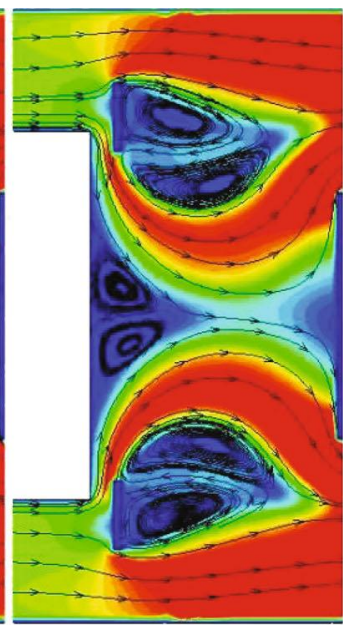

(d) $b / h=0.4$

Figure 11: Velocity in the cavity at section $Z=0 \mathrm{~mm}$ under different $b / h$.

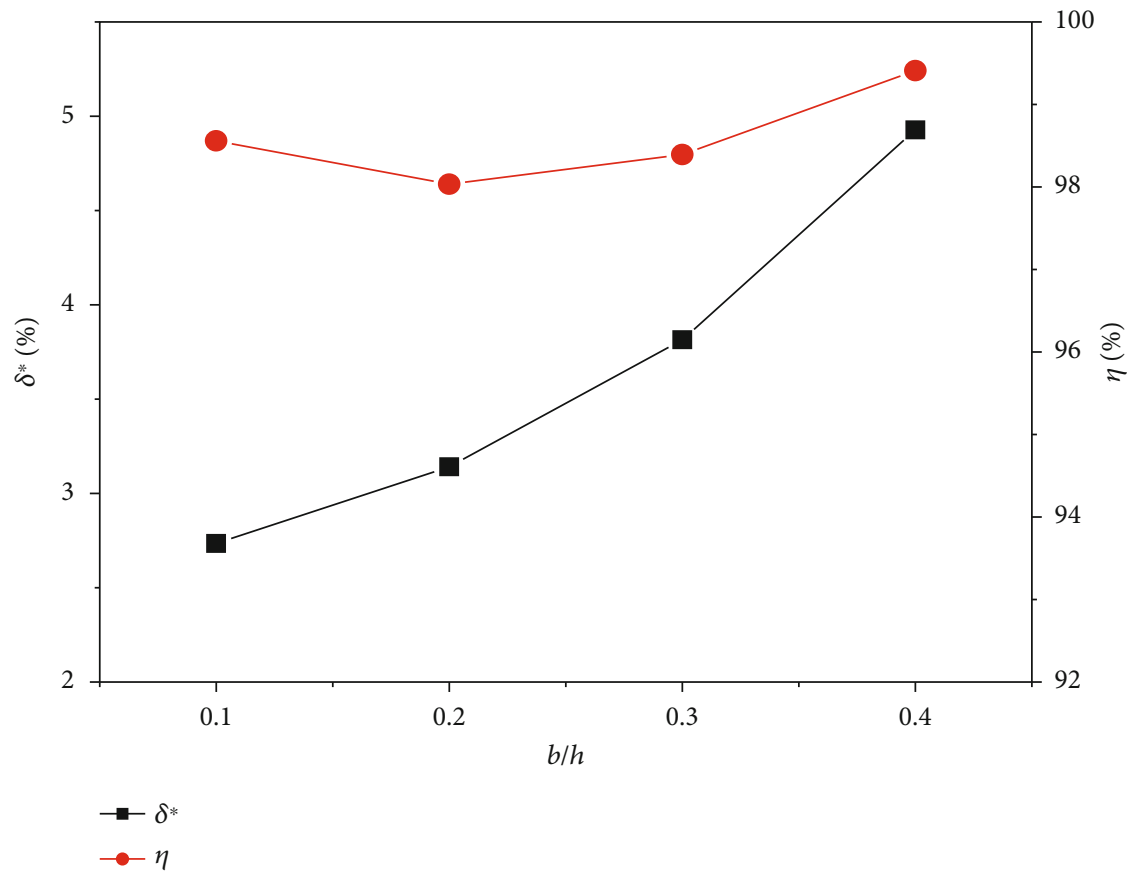

Figure 12: Total pressure loss and combustion efficiency under different $b / h$.

Figure 16 reveals the influence of blunt body height on the velocity field. In the case of no blunt body, doublestructured vortex forms behind the guide vane, and stablestructured vortex is formed near front wall of the cavity. When there exists blunt body, as its height increases, double vortices and its length behind the guide vane gradually decrease. The reason is that with the increase of the blunt body height, the cavity rear position is closer to the inclined struts, the more obvious the extrusion effect of the gas from the cavity vortex with double structure, which shorts double vortex length. At the same time, the greater blunt body height generates the wider backflow area and the larger velocity on the blunt body at both edges, and it is easier to form the double vortices.

Figure 17 shows the effect of blunt body height on total pressure loss and combustion efficiency. When there is no blunt body, total pressure loss is the lowest, total pressure loss increases obviously after the blunt body is set, and the higher the blunt body, the larger the increase in total pressure loss, because as height of the blunt body increases, it generates decrease of its channel height with combustor wall, and the flow resistance increases, which increases total pressure loss. Compared with no blunt body, when $H_{1} / B_{1}<1 / 2$, combustion efficiency has no 


\section{$\begin{array}{lllllllllllllllllllll}v(\mathrm{~m} / \mathrm{s}): & 4 & 8 & 12 & 16 & 20 & 24 & 28 & 32 & 36 & 40 & 44 & 48 & 52 & 56 & 60 & 64 & 68 & 72 & 76 & 80\end{array}$}

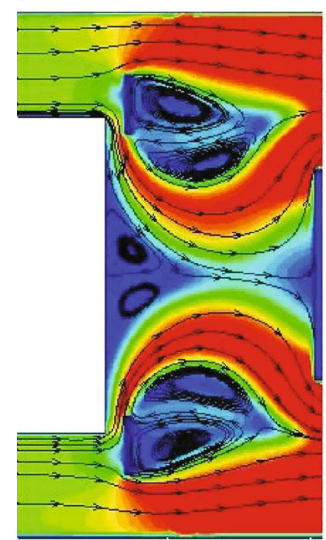

(a) $c / L=0.1$

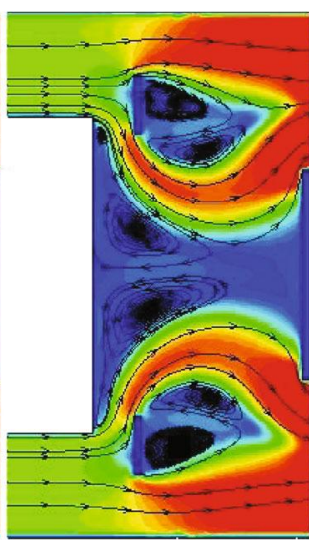

(b) $c / L=0.2$

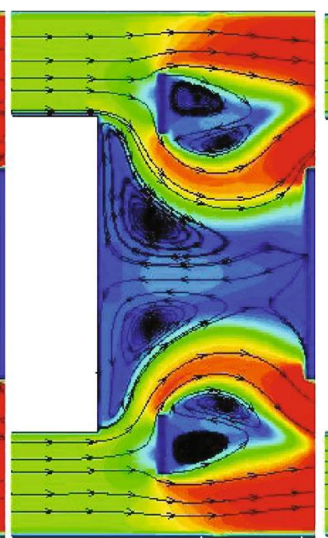

(c) $c / L=0.3$

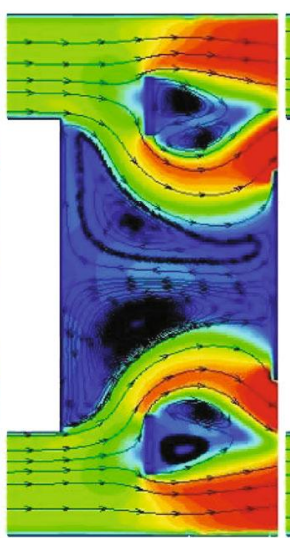

(d) $c / L=0.4$

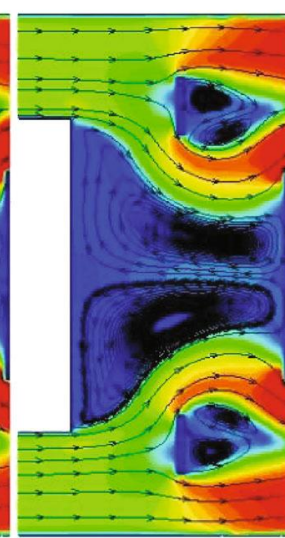

(e) $c / L=0.5$

Figure 13: Velocity distribution at section $Z=0 \mathrm{~mm}$ under different $c / L$.

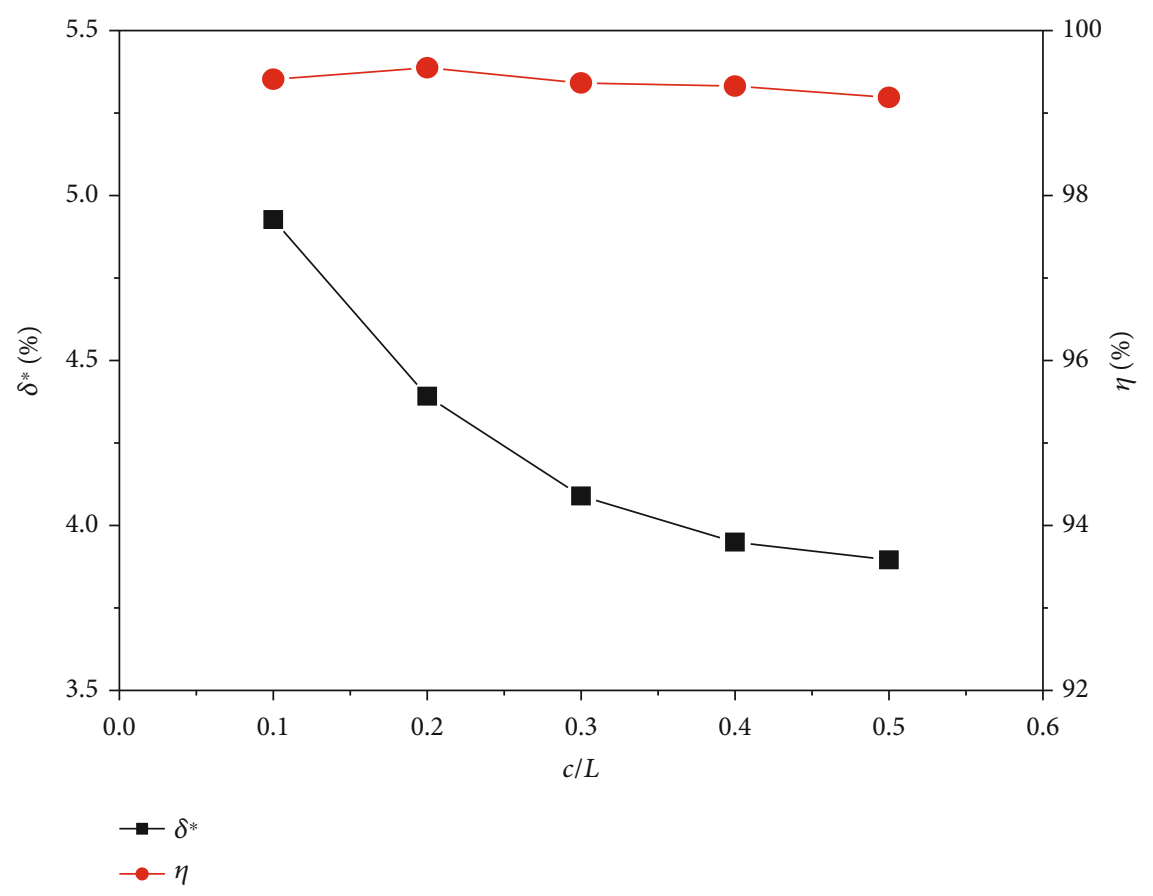

FIgURe 14: Total pressure loss and combustion efficiency under different $c / L$.
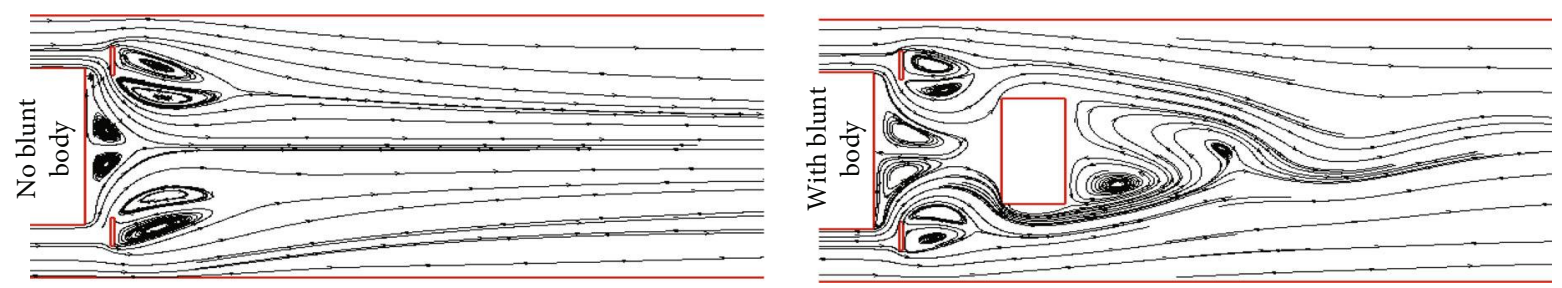

Figure 15: Flow field distribution with or without the blunt body. 
$v(\mathrm{~m} / \mathrm{s})$

$10 \quad 20 \quad 30 \quad 40 \quad 50 \quad 60 \quad 70 \quad 80 \quad 90100110120130140$

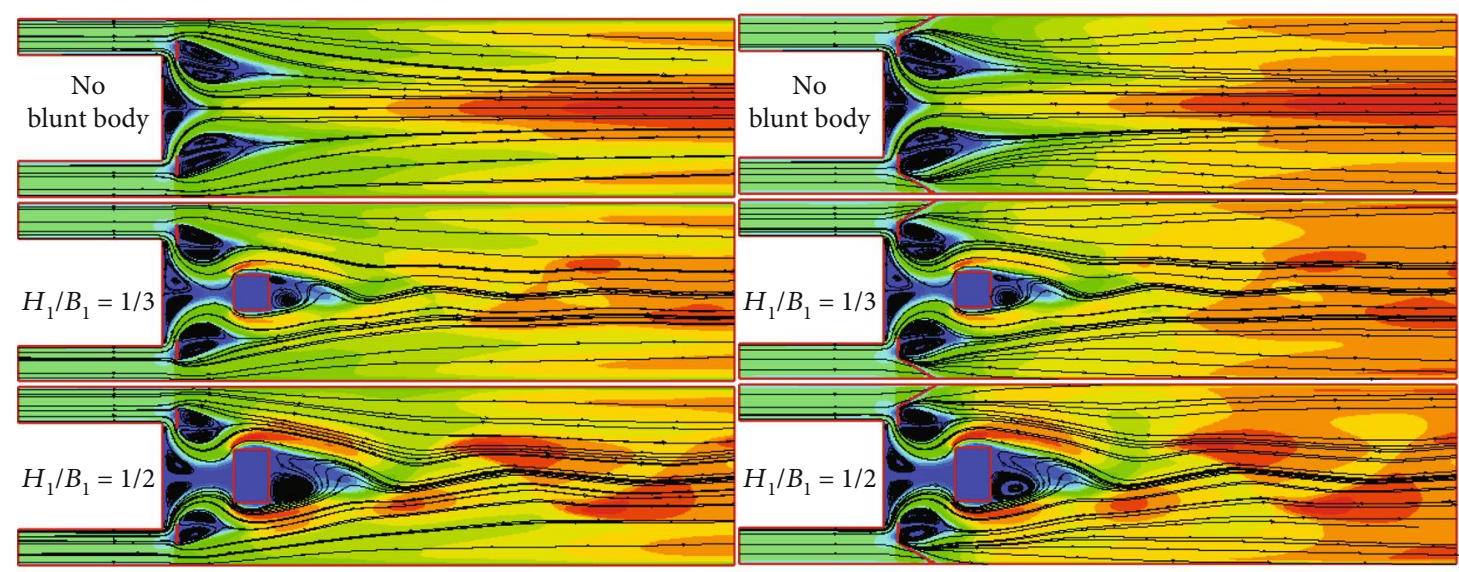

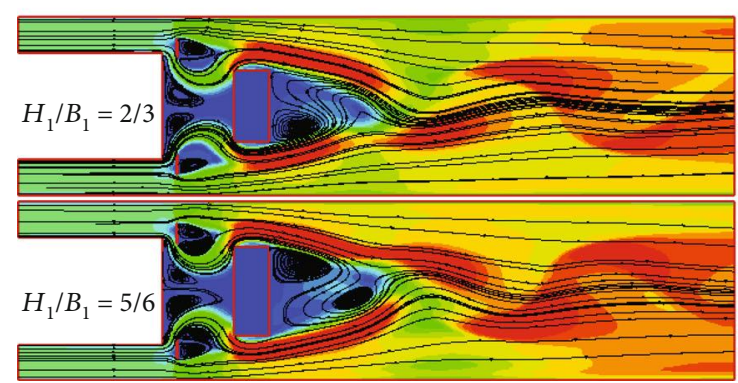

(a)

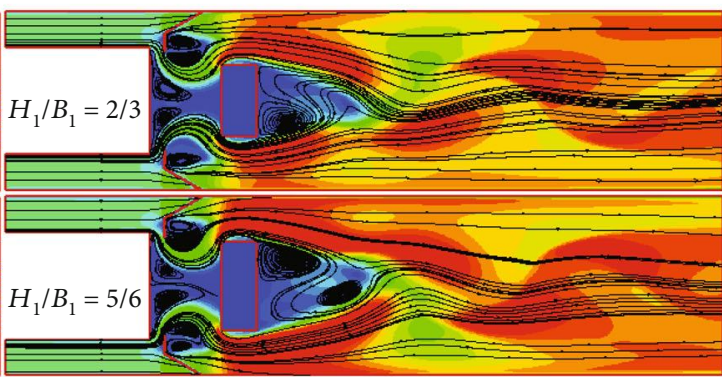

(b)

FIgURE 16: Velocity distribution under different $H_{1} / B_{1}$.

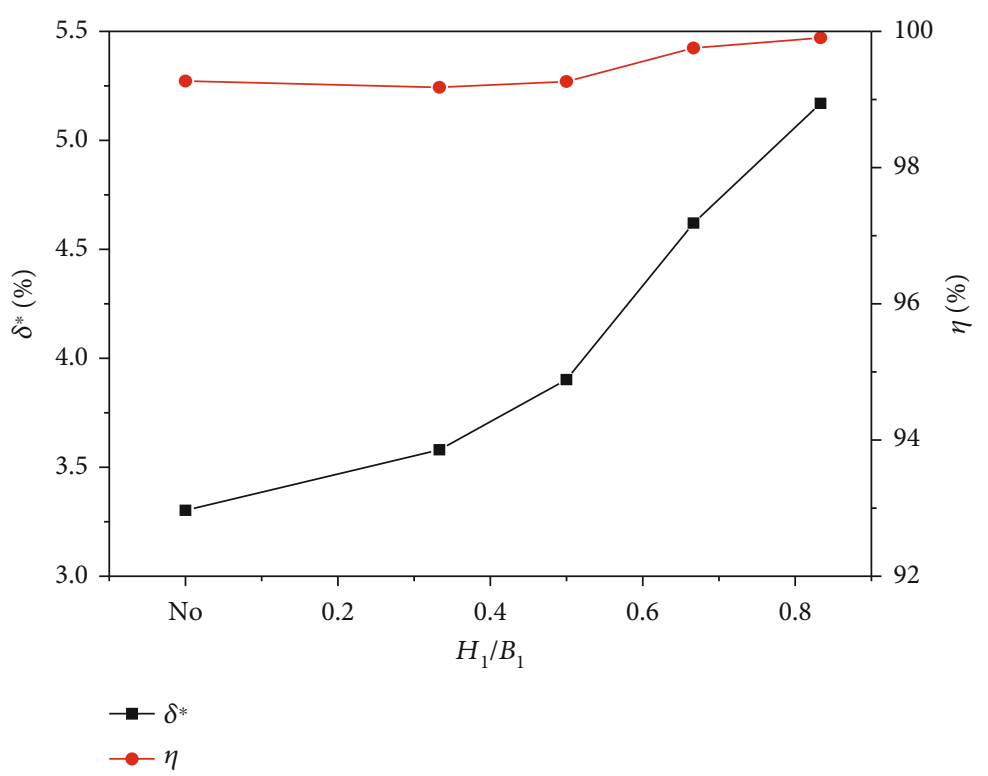

FIgURE 17: Total pressure loss and combustion efficiency under different $H_{1} / B_{1}$.

obvious change. When $H_{1} / B_{1}>1 / 2$, combustion efficiency increases somewhat, and the larger the blunt body height, the higher combustion efficiency.
Comprehensively considering, the optimum structural parameters of the inclined struts are $\alpha=30^{\circ}$ and $\mathrm{BR}=12 \%$; the guide vane and its optimum structural parameters are 
TABLE 3: Specification of calculation conditions.

\begin{tabular}{lr}
\hline Equivalence ratio $\Phi$ & $0.4,0.6,0.8,1.0,1.2,1.4$ \\
Inlet velocity $V /(\mathrm{m} / \mathrm{s})$ & $10,30,50,70,90,110$ \\
Inlet temperature $T_{\text {in }} / \mathrm{K}$ & $300,400,500,600,700$ \\
\hline
\end{tabular}

$v(\mathrm{~m} / \mathrm{s}) \square \mid$\begin{tabular}{l|l|l|l|l|l|l|l|l|l|l|l|l|l|l|l|}
\hline &
\end{tabular}

$10203040506070 \quad 8090100110120130140150160170180190200210220$
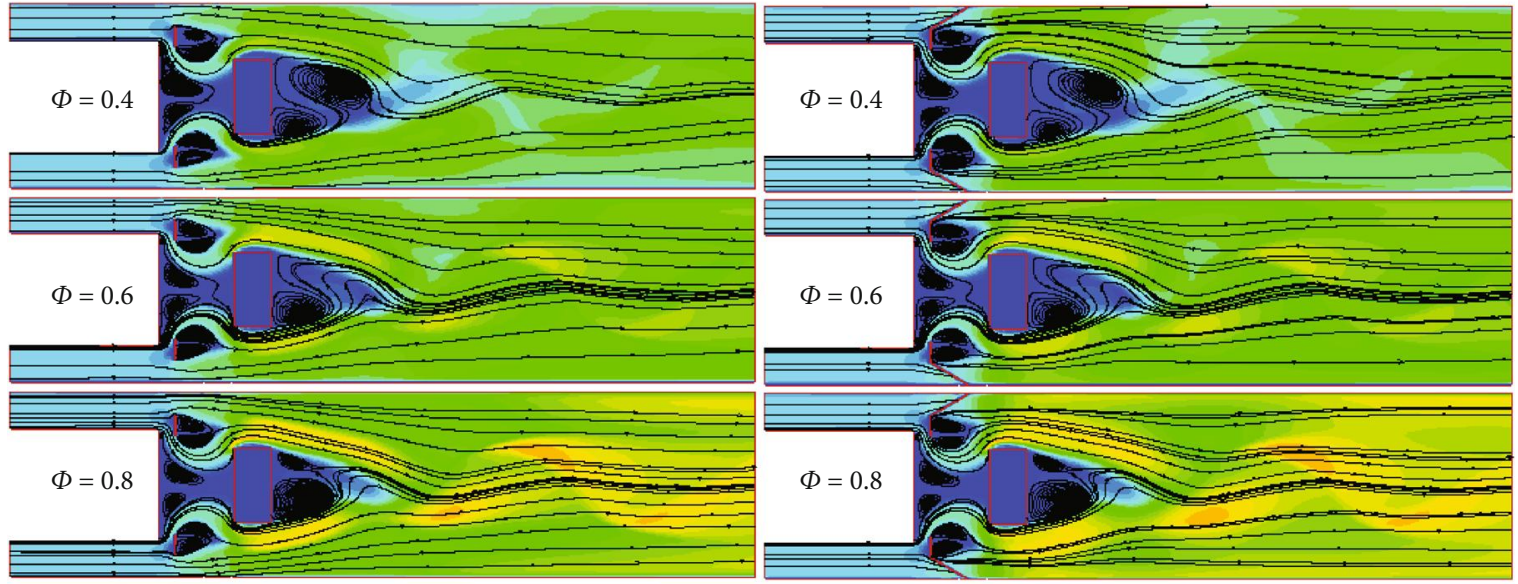

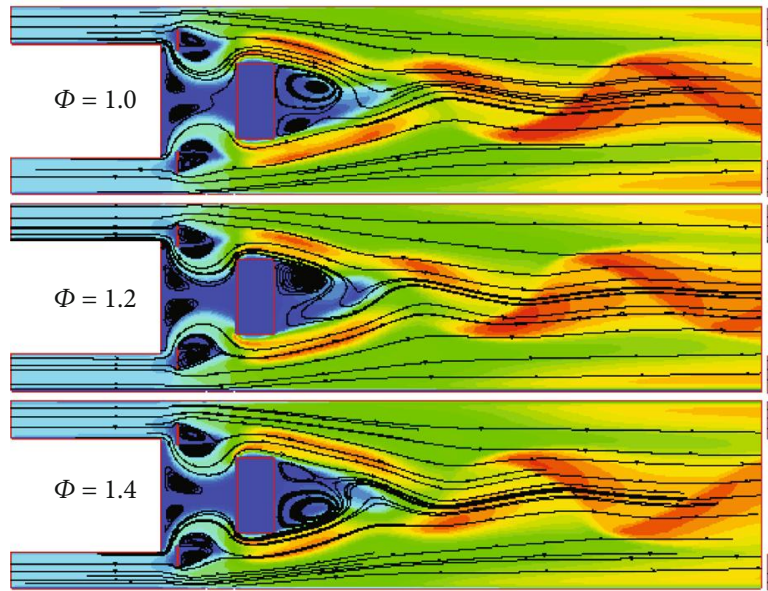

(a)

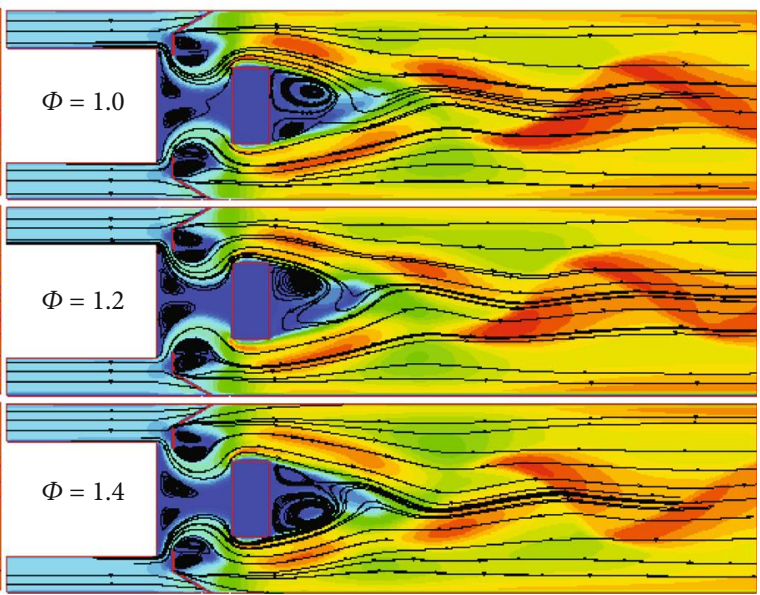

(b)

Figure 18: Velocity field under different equivalent ratio.

as follows: $a / B=0.1, b / h=0.4$, and $c / L=0.2$; blunt body optimal height is $H_{1} / B_{1}=2 / 3$; the blunt body width is parallel to the mainstream direction, and it has little impact on the combustion flow.

4.2. Effect of Inlet Conditions on the Combustion Flow Characteristics of $A V C$. In order to validate whether there will be a desirable dual vortex structure in cavity for various calculation conditions, how do equivalent ratio $\Phi$, inlet velocity $V$, inlet temperature $T$ affect AVC flow field of AVC is studied specifically.

Here are the inlet conditions: (1) changes in methaneair equivalence ratio led to inlet velocity and temperature at $V=50 \mathrm{~m} / \mathrm{s}$ and $T=300 \mathrm{~K}$, respectively. (2) When inlet velocity changes, inlet temperature changes at $T=300 \mathrm{~K}$, with $\Phi=0.6$ of methane-air equivalence ratio; (3) changes in inlet temperature led to inlet velocity at $V=50 \mathrm{~m} / \mathrm{s}$ with $\Phi=0.6$ in methane-air equivalence ratio. Table 3 shows calculation condition specifications.

For analyzing enhancement of heat transfer, the author introduces synergy principle generated within field of velocity and temperature [22]. The field synergy principle states that the convective heat transfer performance depends not only on the velocity and temperature fields of the fluid, but also on the angle between them. Synergy principle in transfer of convective heat and field gains verification through 


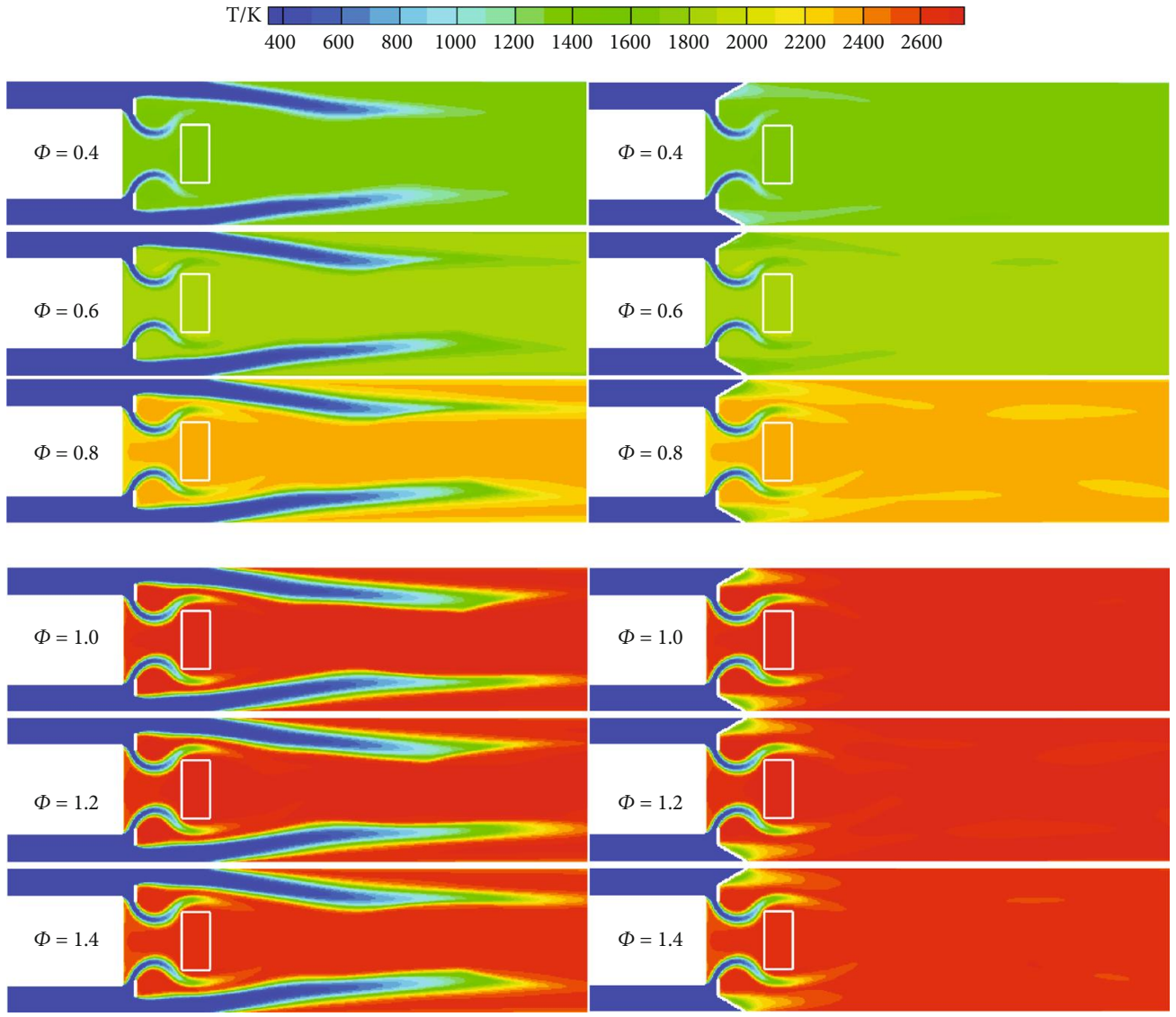

(a)

(b)

Figure 19: Temperature field under different equivalent ratio.

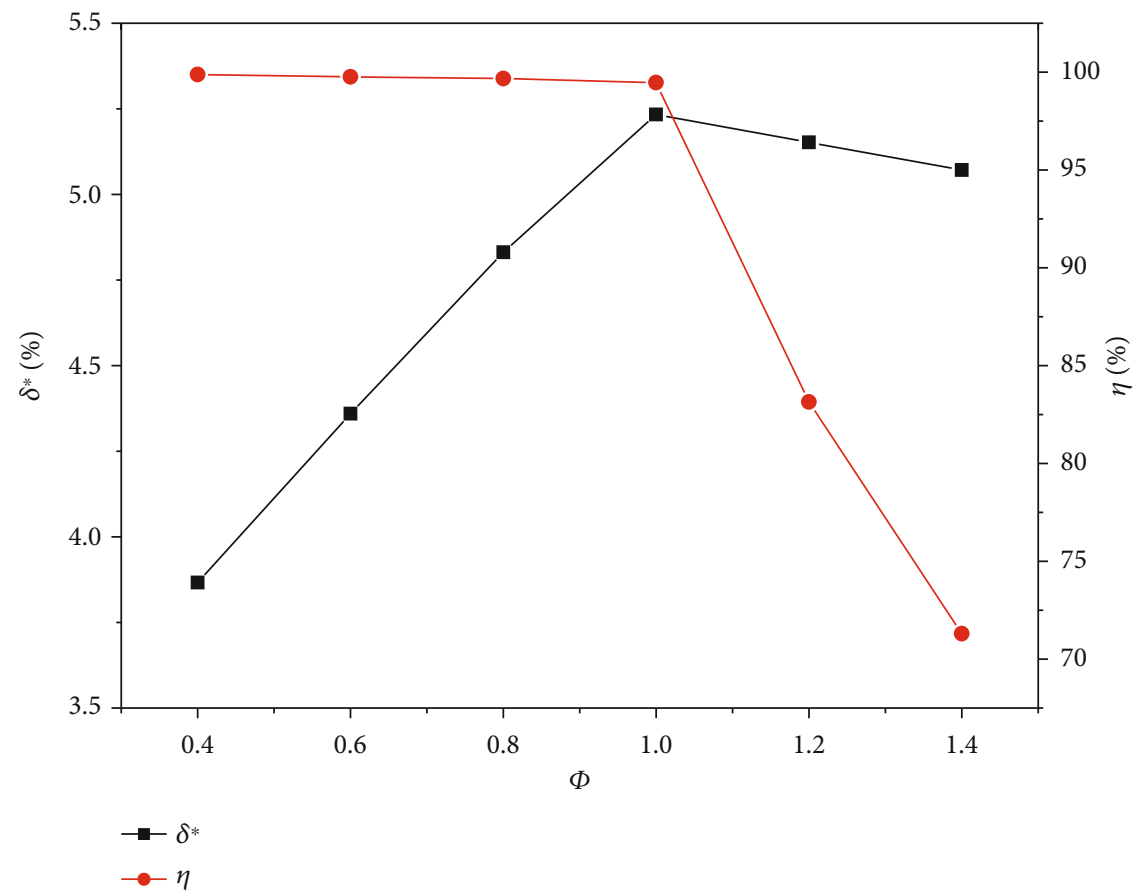

Figure 20: Total pressure loss and combustion efficiency under different equivalent ratio. 


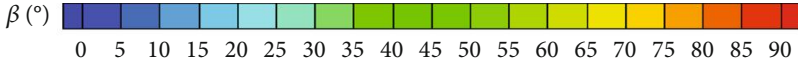

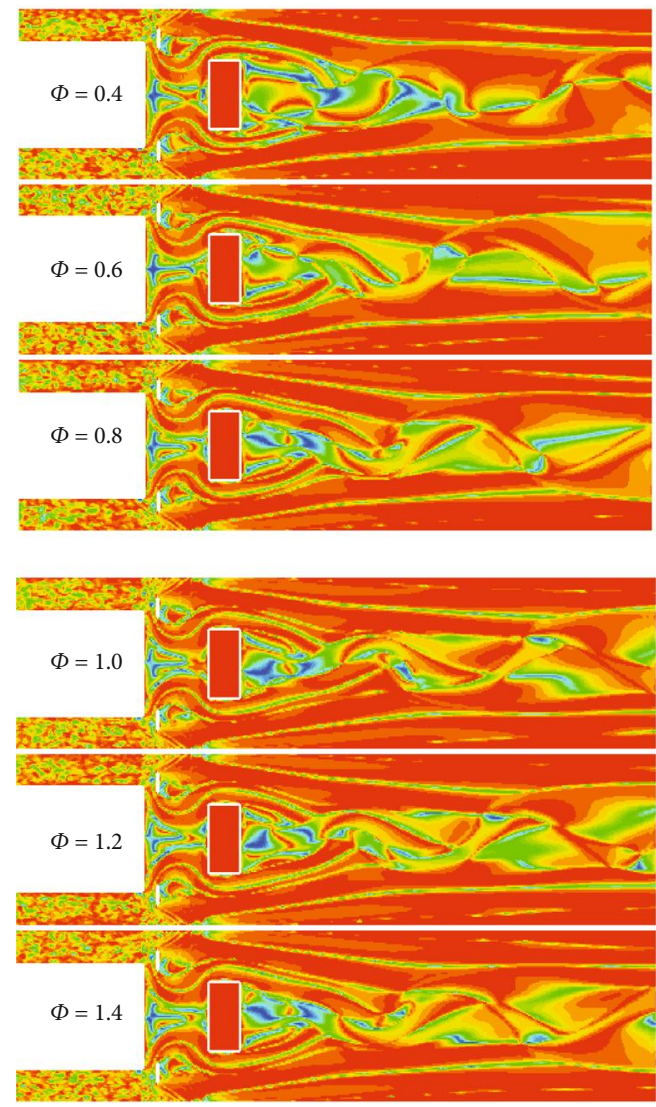

(a)
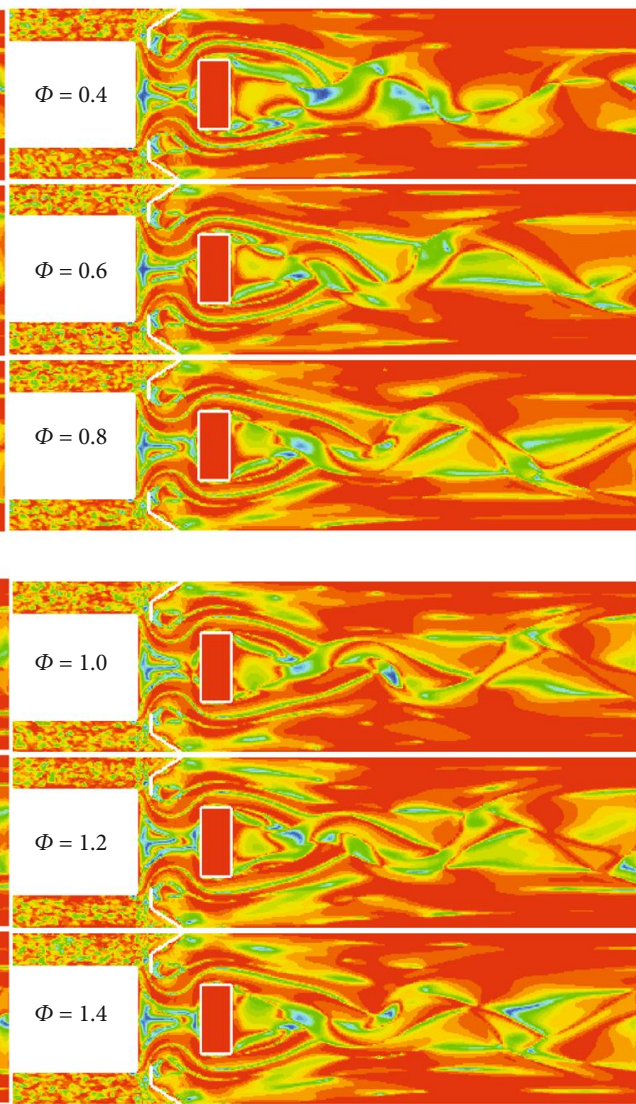

(b)

Figure 21: Average synergy angle distribution under different equivalent ratio.

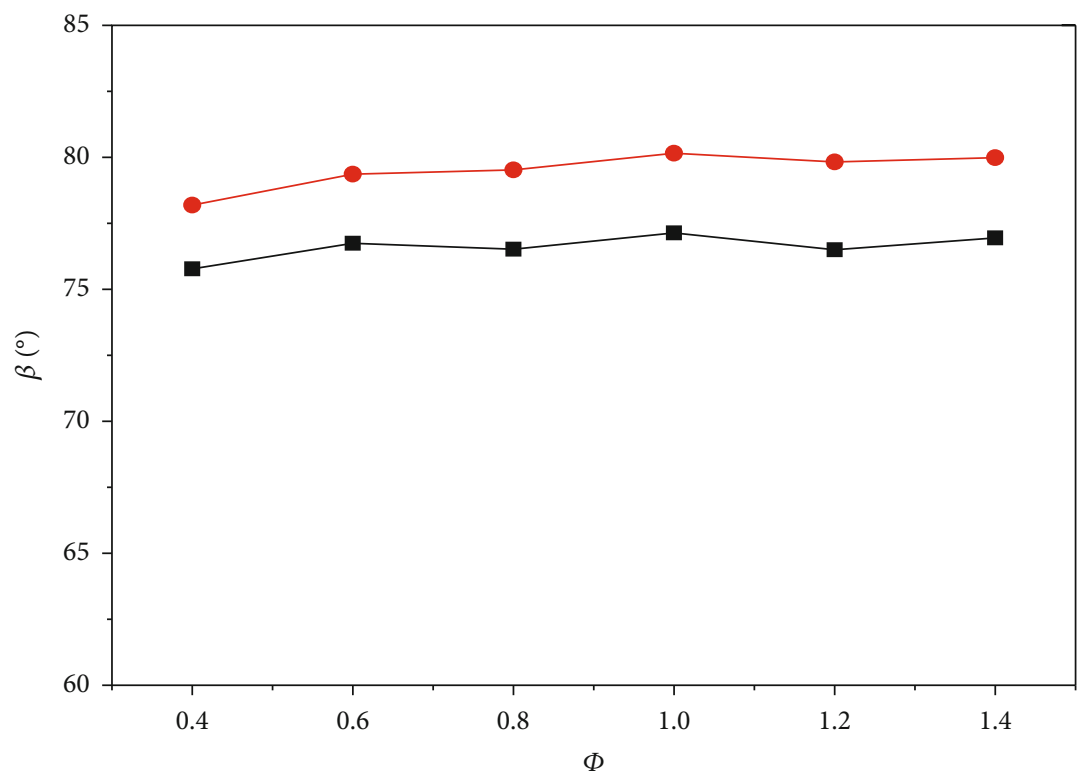

$\rightarrow$ Area-average $(z=0 \mathrm{~m})$

- Volumn-average

FIGURE 22: Volume average synergy angle and area average synergy angle distribution under different equivalent ratio. 


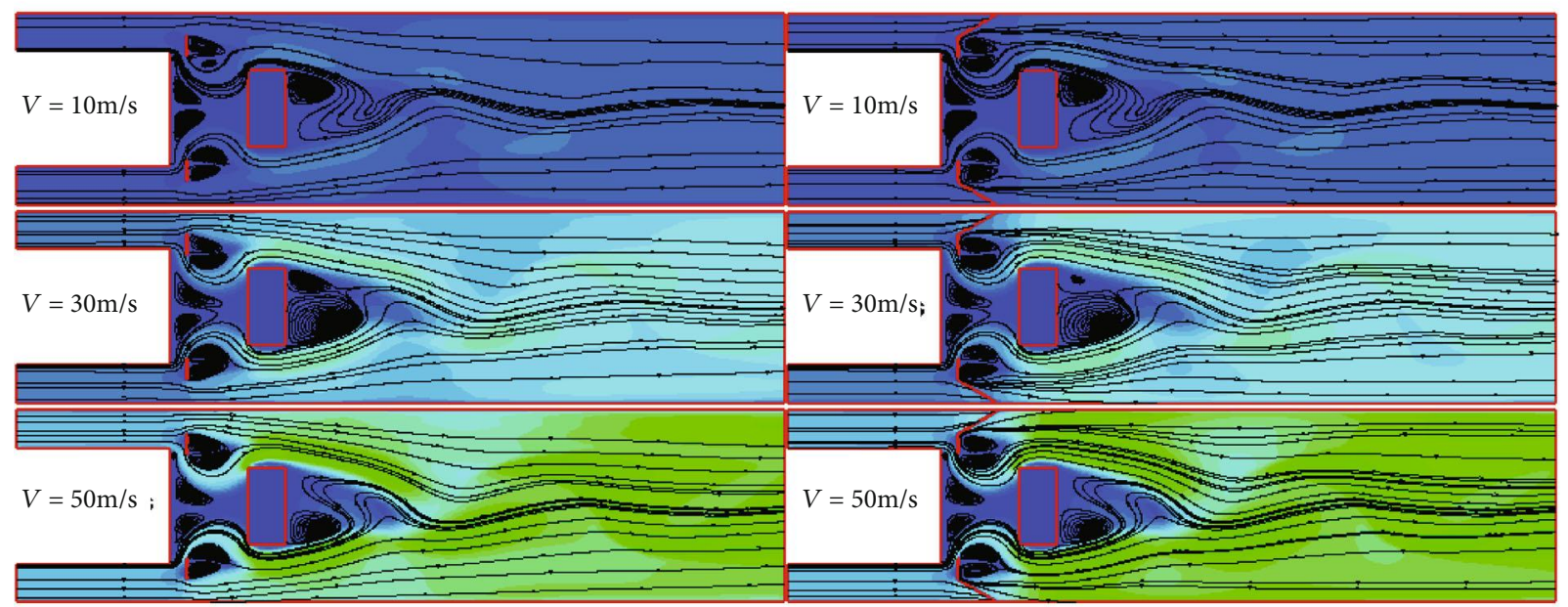

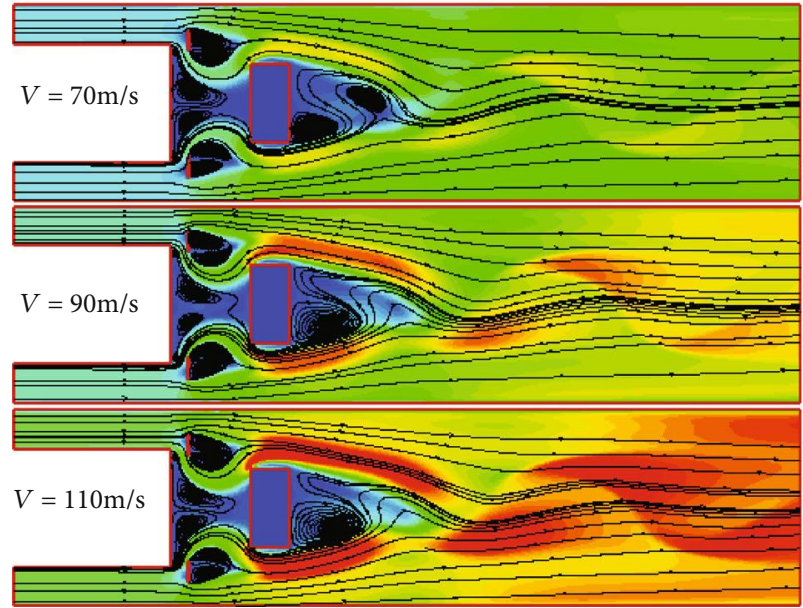

(a)

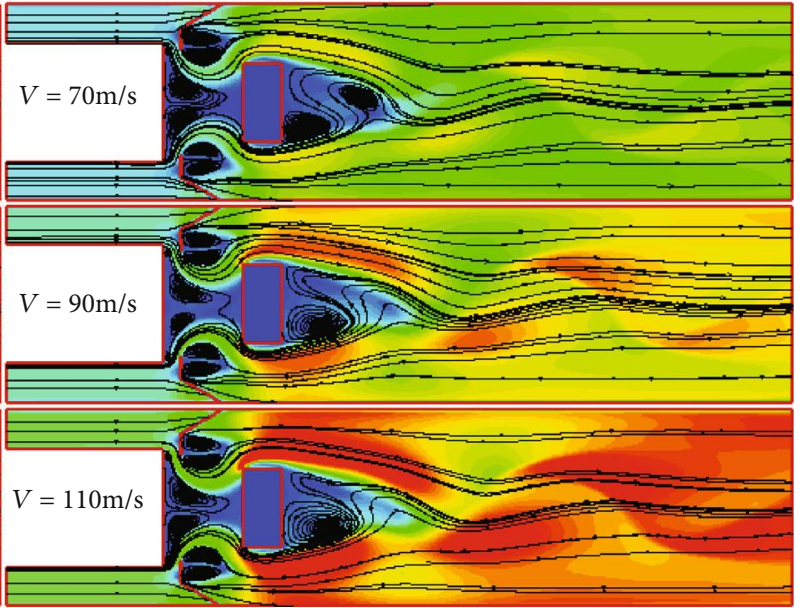

(b)

Figure 23: Velocity field under different inlet velocities.

numerical calculation and experiment [23, 24]. Between velocity vector $U$ and gradient $\nabla T$ in temperature, synergy angle is $\beta$. The larger the synergy angle value is, the worse the synergy ability is. The synergy angle expression is as follows [25]:

$$
\begin{aligned}
\beta & =\arccos \frac{U \nabla T}{|U||\nabla T|} \\
& \arccos \frac{u(\partial T / \partial x)+v(\partial T / \partial y)+w(\partial T / \partial z)}{\sqrt{u^{2}+v^{2}+w^{2}} \sqrt{(\partial T / \partial x)^{2}+(\partial T / \partial y)^{2}+(\partial T / \partial z)^{2}}} .
\end{aligned}
$$

4.2.1. Effect of Equivalence Ratio $\Phi$ on the Characteristics of $A V C$. Figure 18 is the effect of different equivalent ratio $\Phi$ on the velocity field. Under different equivalent ratio, stable double vortices can be formed near the cavity front wall and behind the guide vane, and a stable backflow region can also be formed behind the blunt body. However, the size, position, and shape of the double vortices formed near the cavity front wall have some change. With the increase of the equivalent ratio, the length of the backflow region behind the blunt body decreases, and the velocity behind the blunt body increases first and then decreases. When the equivalent ratio $\Phi=1.0$, the velocity increment is the largest, and the range of the high velocity region is the widest. Figure 19 reveals how different equivalent ratio $\Phi$ affects the temperature field. $\Phi<1$ is lean fuel combustion state, oxygen is sufficient, and the fuel can be fully burned, while the fuel mass fraction in the mixture is lower, and the heat release from combustion is less. The excessive air absorbs some heat, so the temperature in the combustor is lower, and the smaller the $\Phi$ is, the lower the overall temperature of the combustor is. $\Phi>1$ is lean oxygen combustion state, the amount of fuel in the mixture is too high to fully react, some fuels do not participate in the reaction, they can absorb some heat, and the larger $\Phi$ is, the smaller the range of high temperature in 


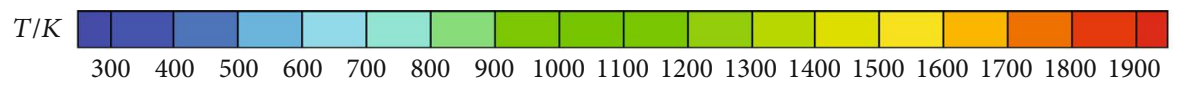

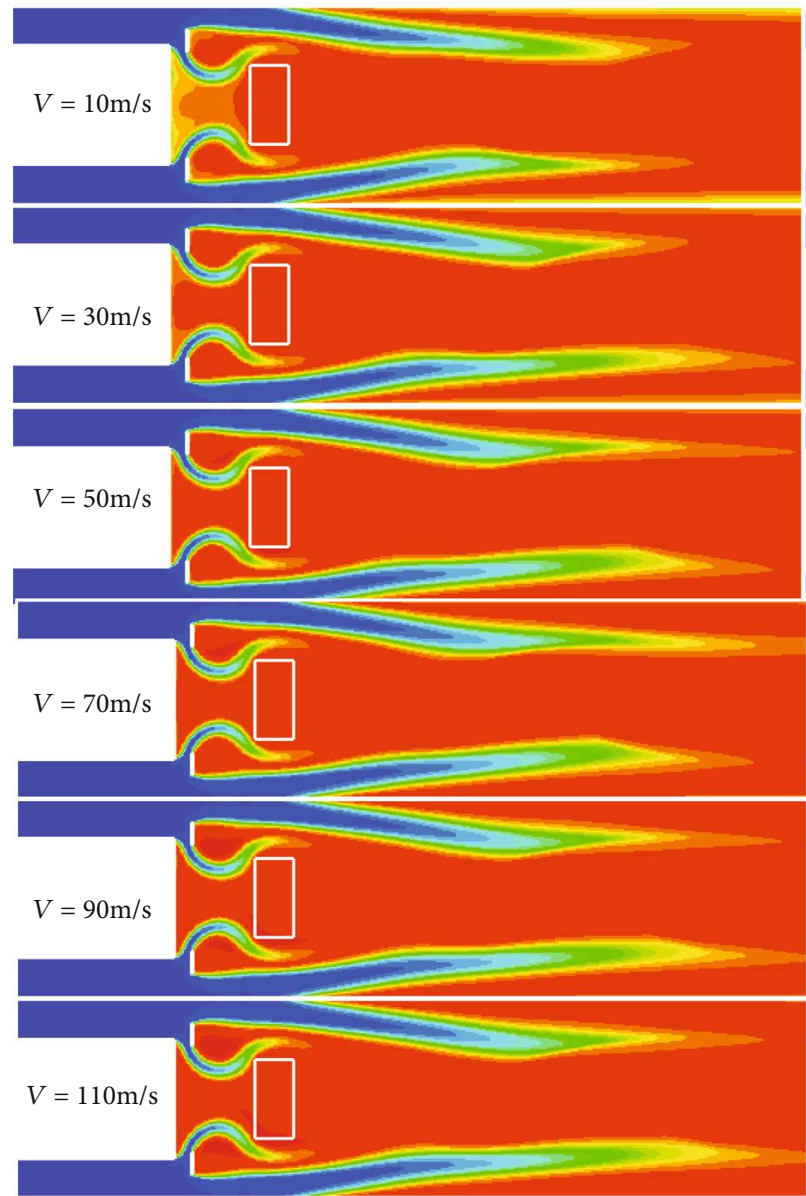

(a)

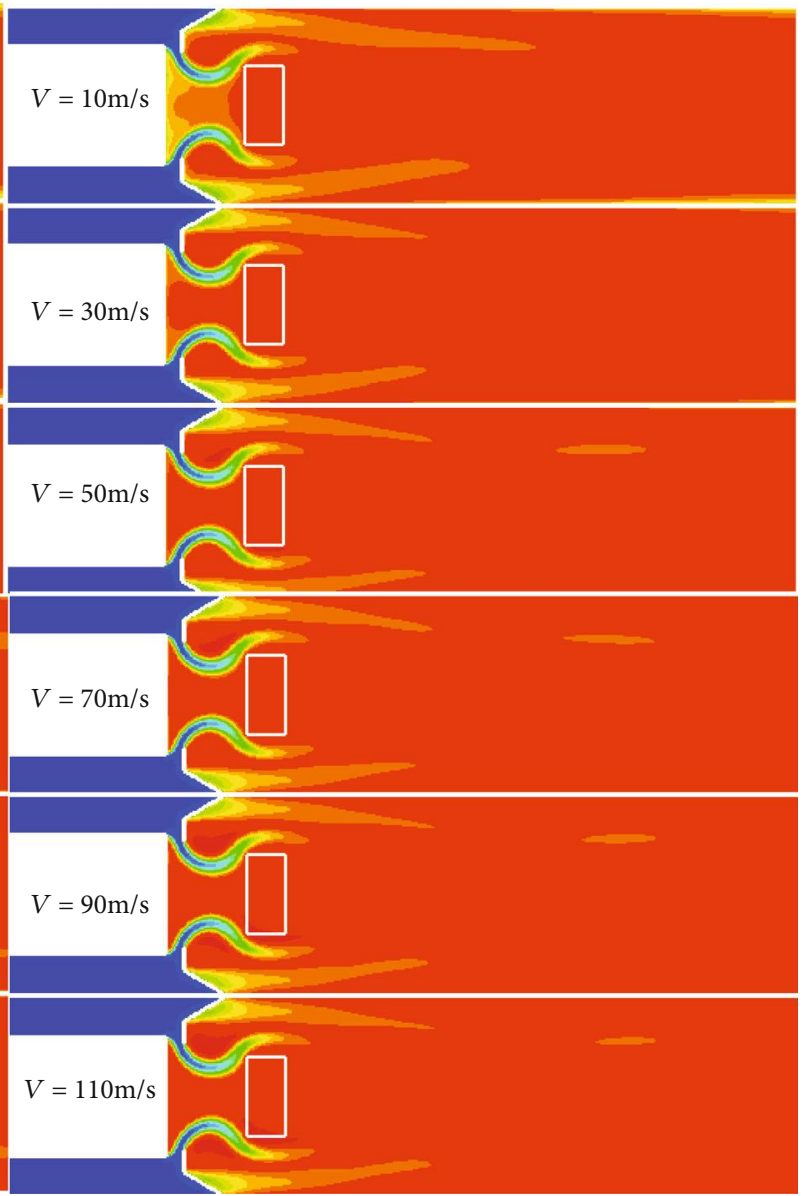

(b)

FIgure 24: Temperature field under different inlet velocities.

the combustor is. When $\Phi=1$, the fuel and air can react completely, and the temperature in the combustor is obviously higher than that of lean combustion.

Figure 20 shows total pressure loss and combustion efficiency under different equivalent ratio. When $\Phi=1$, total pressure loss is maximum, and it is due to the maximum heat release and the maximum overall temperature rise in the case of the complete reaction. Its temperature is significant to gas viscosity, and the gas viscosity increases when temperature and the gas flow resistance increase. When $\Phi<1$, the heat release from combustion decreases greatly with the decrease of equivalent ratio. The combustor temperature decreases significantly, the gas viscosity decreases rapidly, and total pressure loss also decreases rapidly. But when $\Phi>1$, the excessive unreacted fuel can take away some heat, and the overall temperature and the gas viscosity decrease, so total pressure loss decreases. When $\Phi=0.4-1.0$, combustion is lean fuel, and oxygen is sufficient, fuel can be fully burned, so combustion efficiency is very high, and it exceeds $99 \%$. When $\Phi>1$, combustion is poor oxygen, the fuel is not fully combustible, and a large amount of unburned fuel is blown directly out of the combustor.
Figure 21 reveals the area average synergy angle distribution at different section under different equivalent ratio. Figure 22 shows the area average synergy angle distribution at section $Z=0 \mathrm{~mm}$ and the volume of synergy angle in average. When the equivalent ratio increases, synergy angle in average volume increases, the synergy between the field of velocity and the temperature is deteriorated. In the case of $\Phi>1.0$, the variation of synergy angle in average is not obvious. The reason is that when equivalent ratio increases, backflow region and its velocity and length decrease. Scope of high temperature in combustor decreases when velocity changes, which leads to the variation in small-region synergy angle behind the blunt body.

4.2.2. Effect of Inlet Velocity on the Characteristics of AVC. According to Figure 23, flow field distributed at different inlet velocities is shown. When inlet velocity increases, a stable double vortex structure is formed without influences from mainstream flow. Backflow regional length of the blunt body varies little and barriers its formation of symmetrical double vortices. Besides, one-sided vortex is usually broken by stretching. 


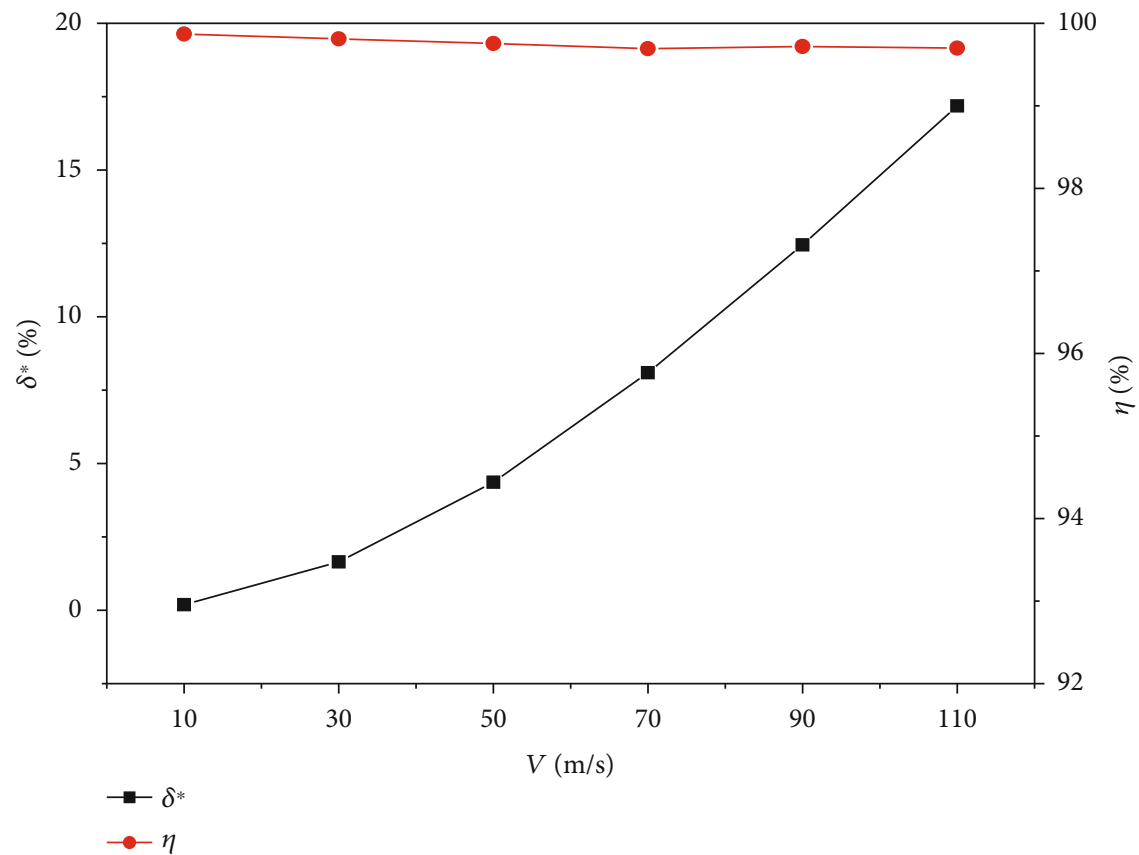

Figure 25: Total pressure loss and combustion efficiency under different inlet velocities.
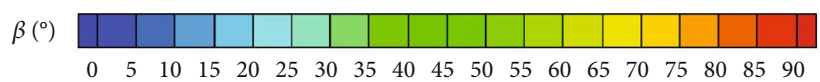

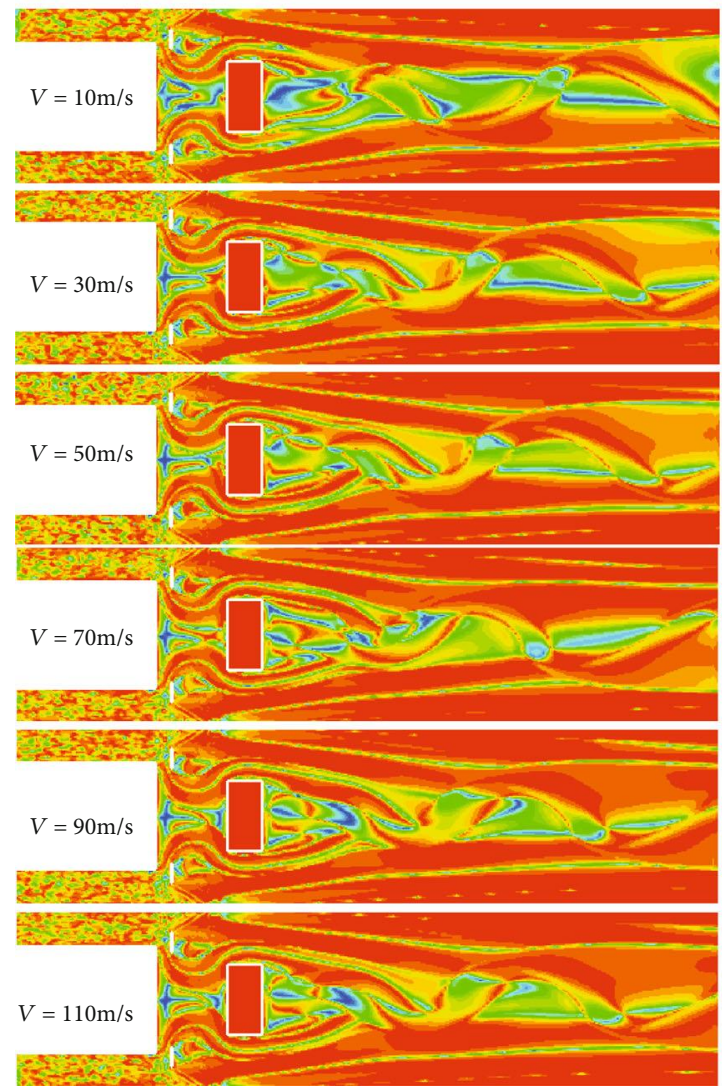

(a)

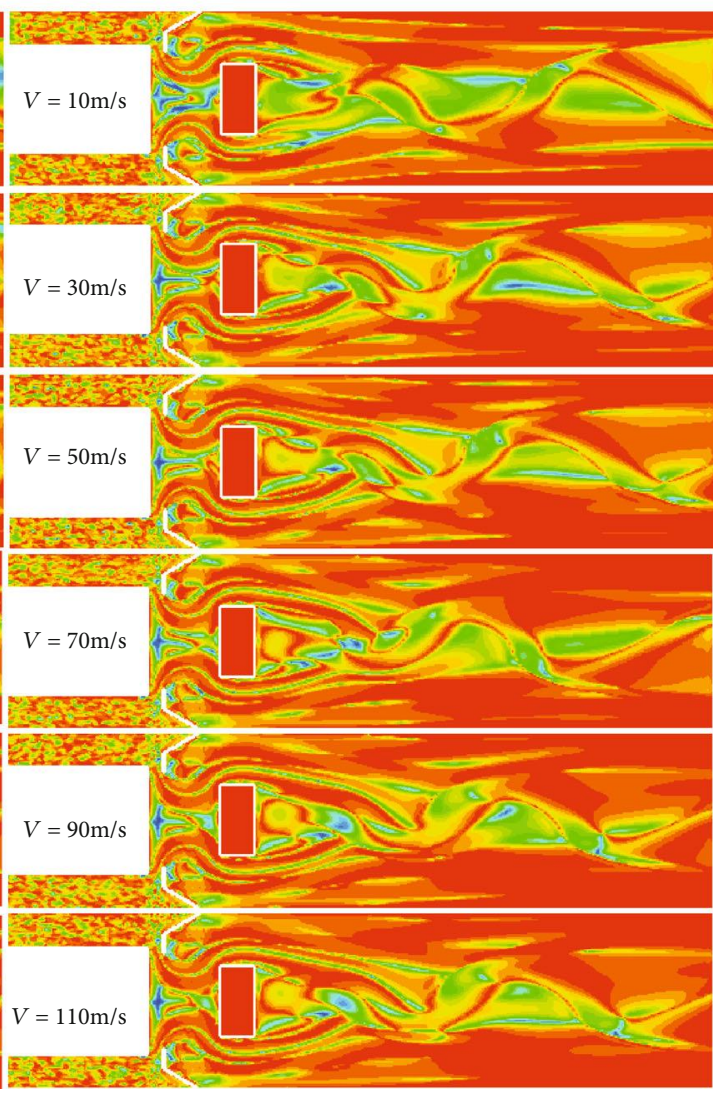

(b)

FIGURE 26: Synergy angle distribution under different inlet velocities. 


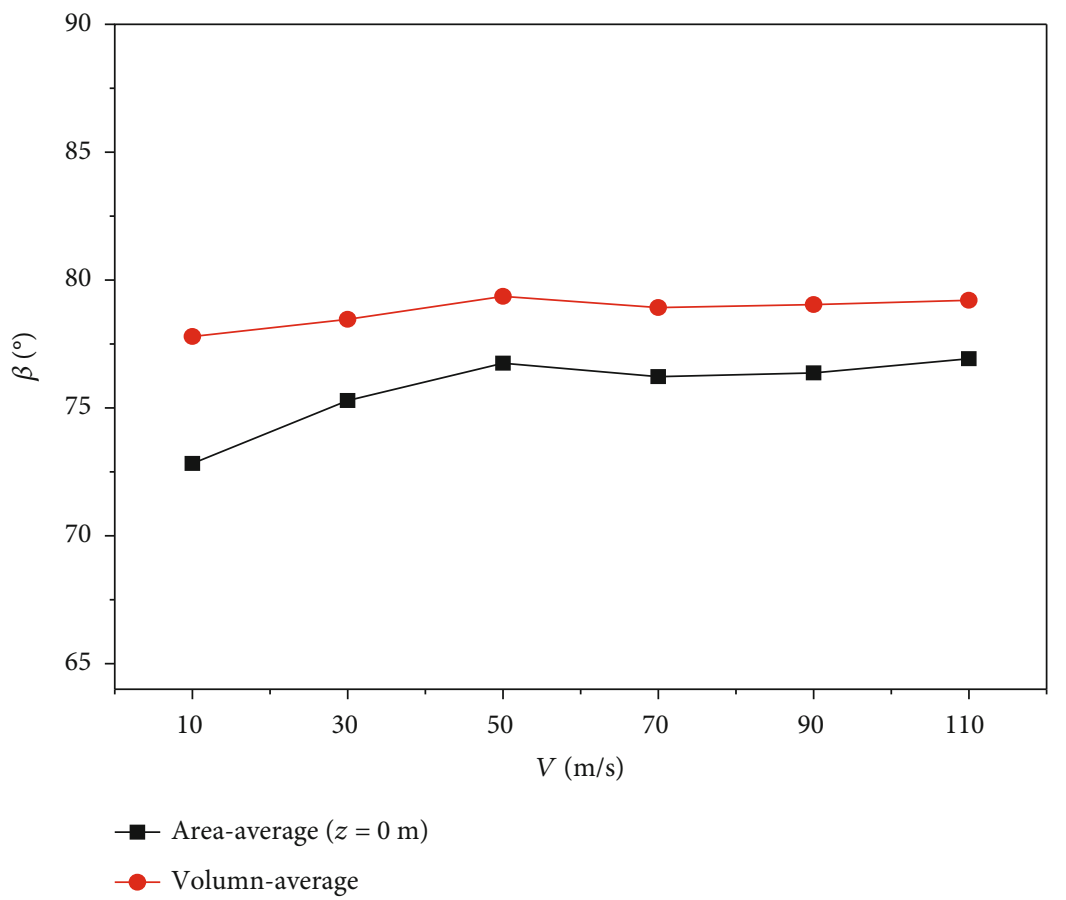

FIGURE 27: Volume average synergy angle and area average synergy angle under different inlet velocities.

$V(\mathrm{~m} / \mathrm{s})$

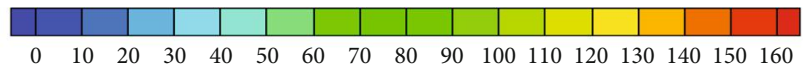

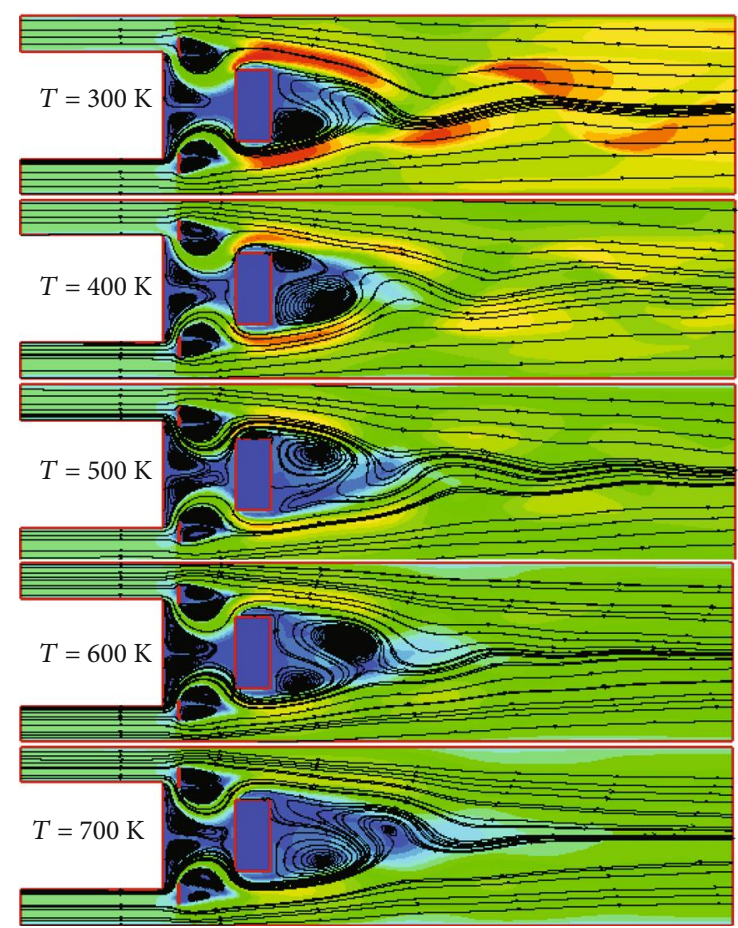

(a)

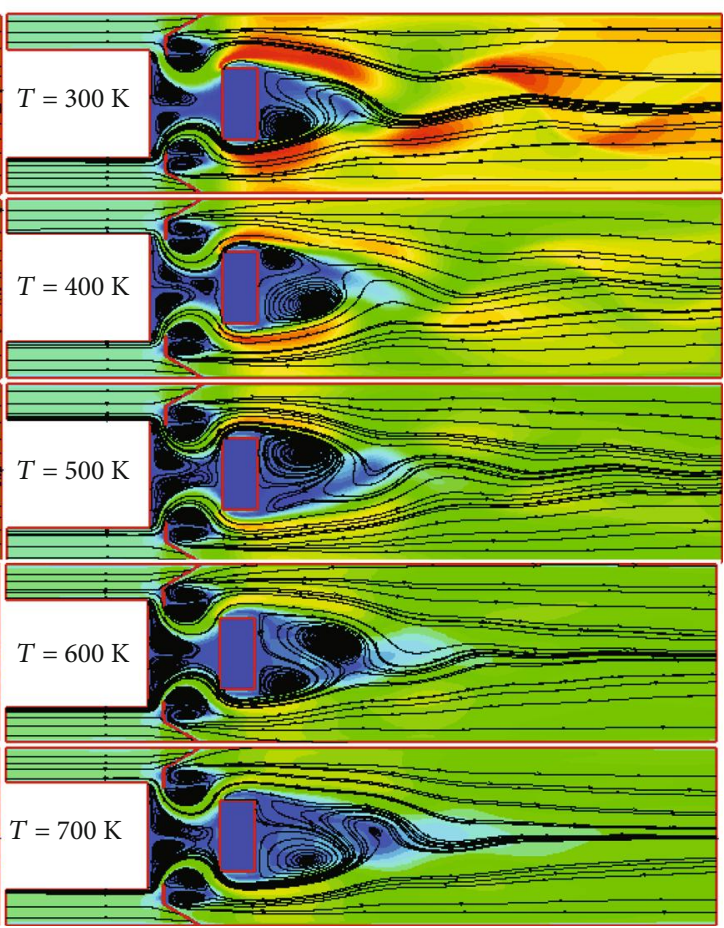

(b)

Figure 28: Velocity field under different inlet temperatures.

Figure 24 shows temperature distributed at different inlet velocities. In the cavity, when flow velocity varies, high temperature position behind blunt body changes. When $V=10$ $\mathrm{m} / \mathrm{s}$, there is less gas flows and less heat release reaction and lower transfer degree in heat and mass; the temperature near the cavity front wall is about $1500 \mathrm{~K}$, and its temperature 

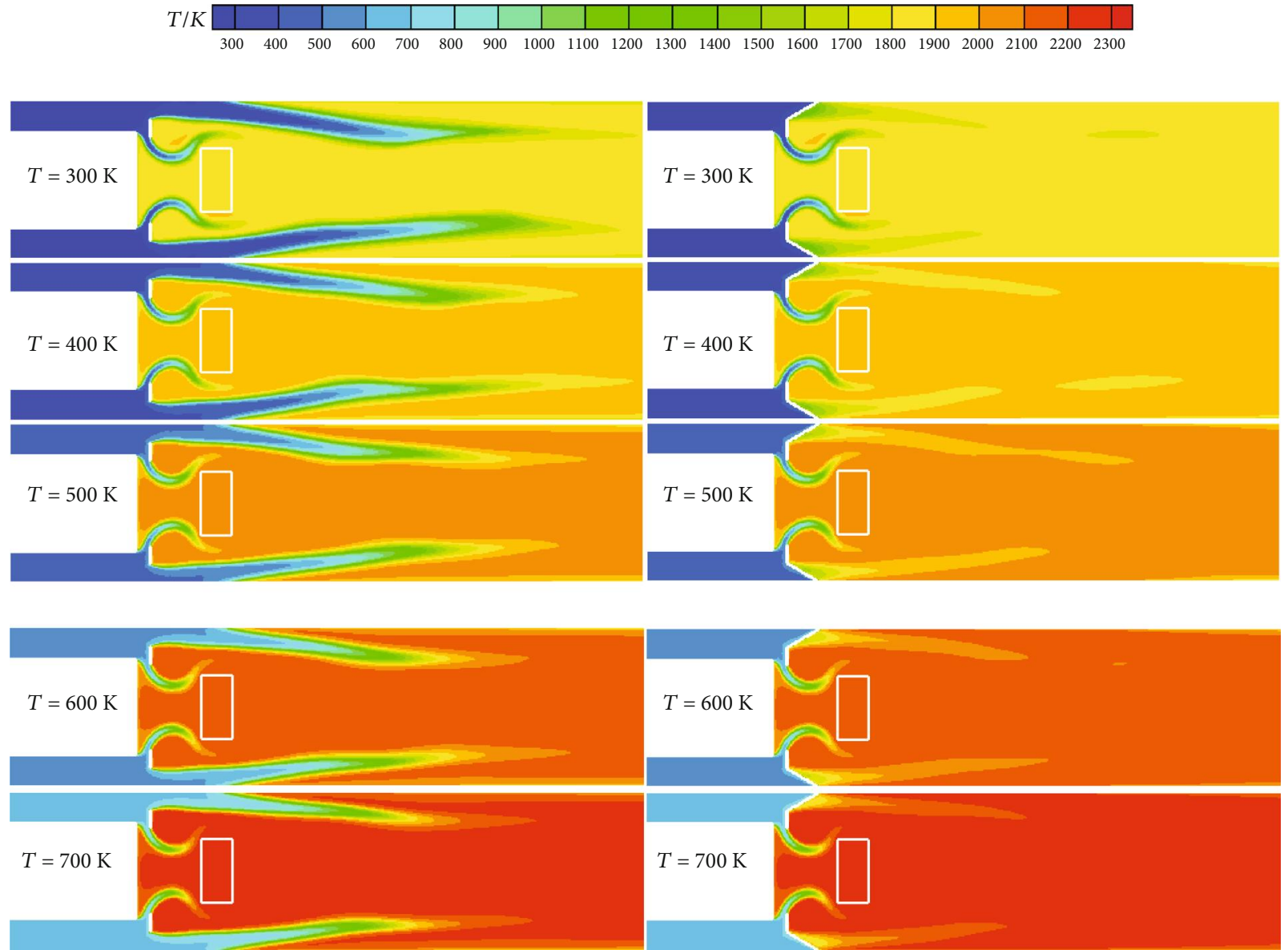

(a)

(b)

Figure 29: Temperature field under different inlet temperatures.

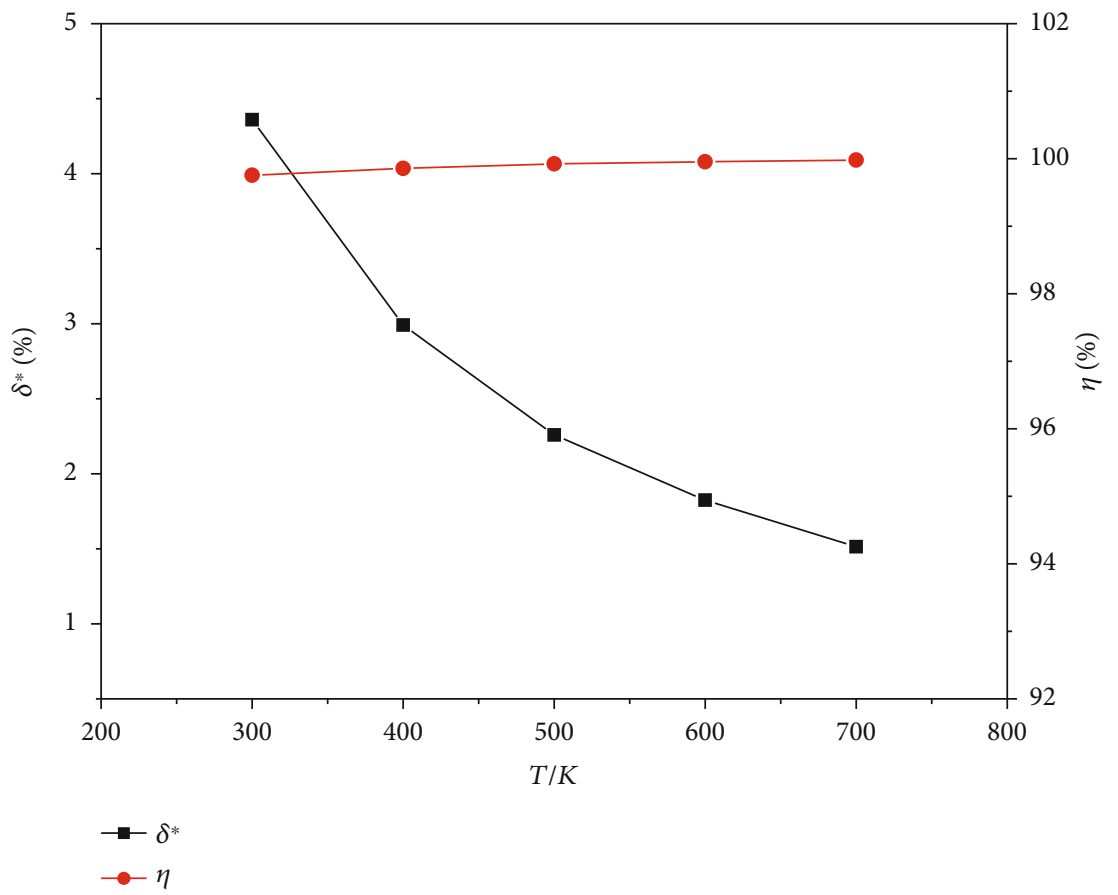

FIgURE 30: Total pressure loss and combustion efficiency under different inlet temperatures. 

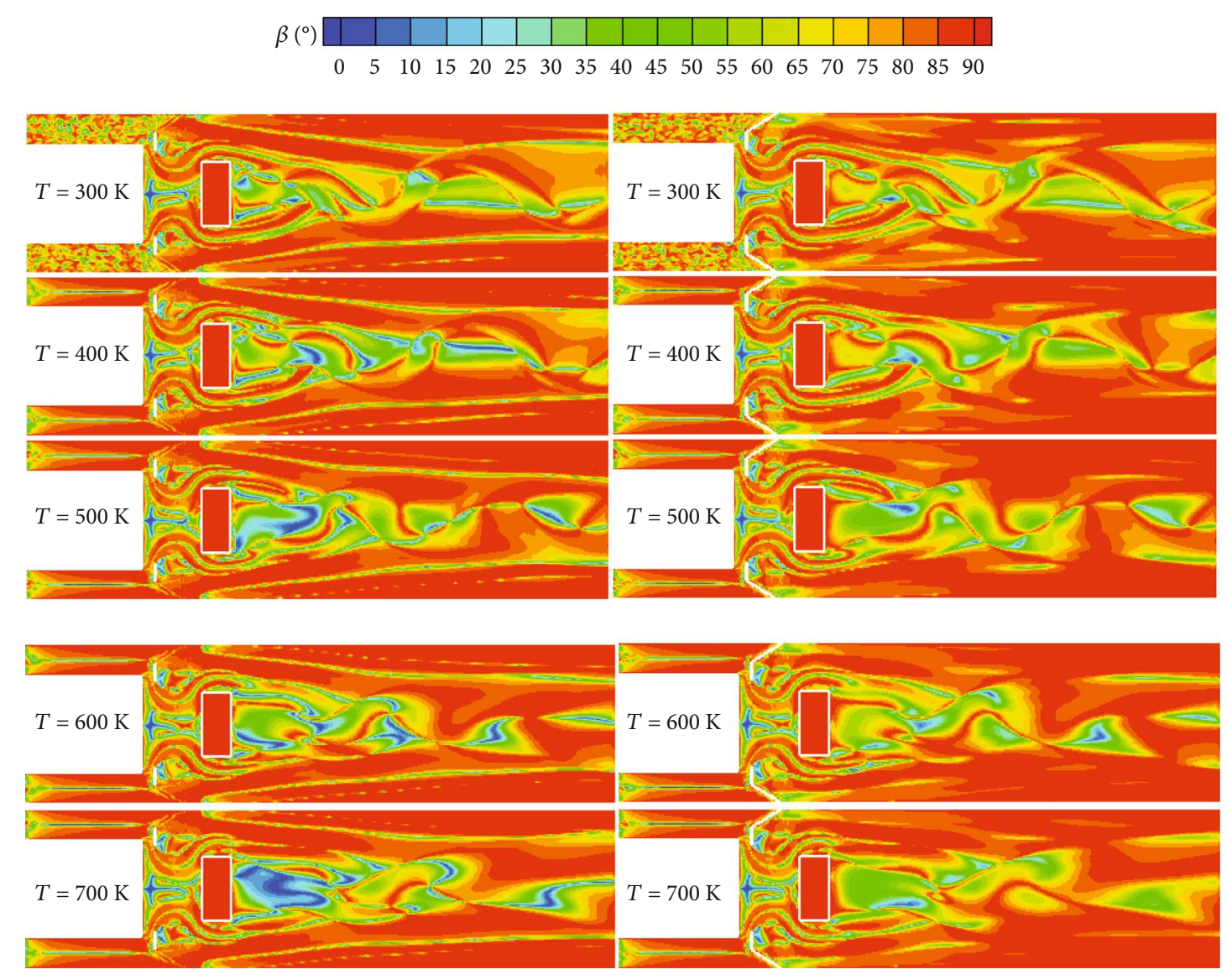

FIGURE 31: Synergy angle distribution under different inlet temperatures.

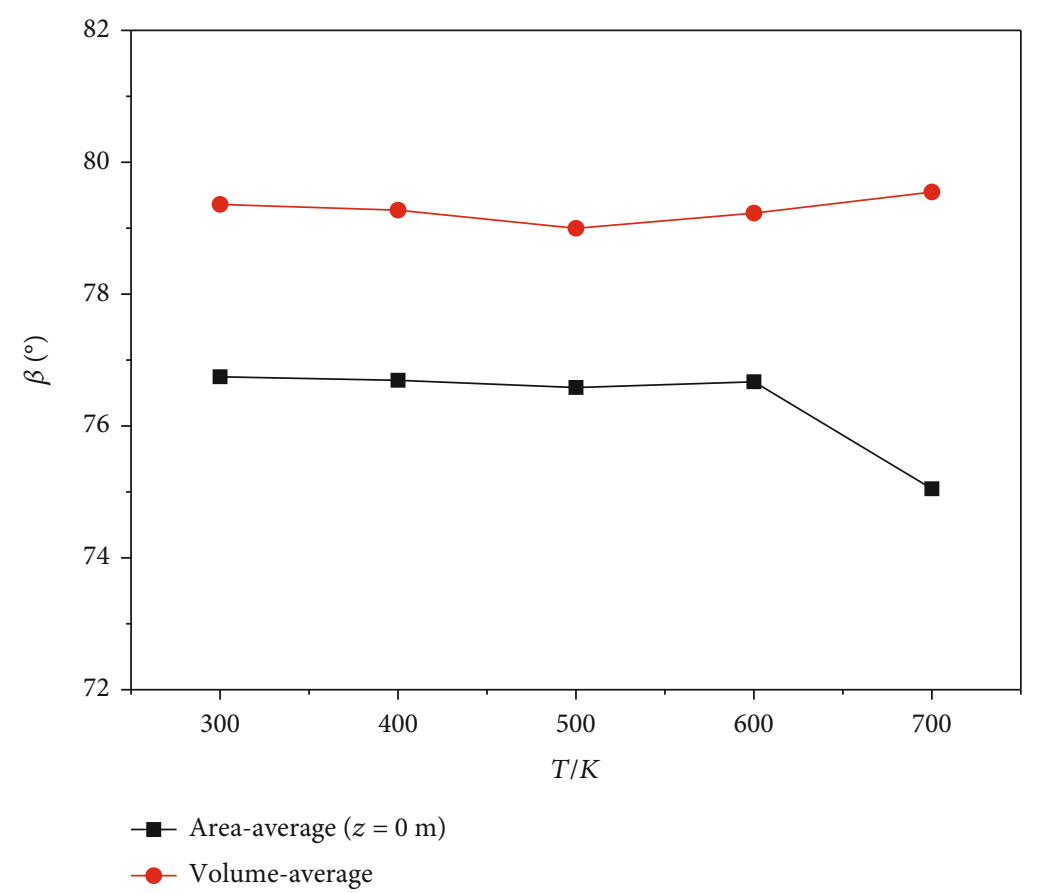

FIGURE 32: Volume average synergy angle and area average synergy angle under different inlet temperatures. 
increases by flow direction. Near the front wall of the blunt body, the mainstream velocity is relatively small, the entrainment capacity of the double vortices behind the guide vane is weak, the heat and mass transfer is also weak, and temperatures of the secondary vortex and main vortex are $1700 \mathrm{~K}$ and $1800 \mathrm{~K}$, respectively. Increase in inlet velocity generates the increase in TVC and kinetic energy with turbulence, and the transfer of corresponding heat and mass enhances, which increases the temperature of the double vortices behind the guide vane. At section $Z=0 \mathrm{~m}$, turbulent kinetic energy appears to be uniform behind the blunt body, and the transfer in heat and mass is also different behind the blunt body. At section $Z=0.007 \mathrm{~m}$, turbulent kinetic energy behind the inclined struts is larger, and the stronger the transfer in heat and mass, the more uniform the distributed temperature.

Figure 25 shows how different inlet velocities affect its total pressure loss and efficiency in combustion. It shows that pressure in loss increases when inlet velocity increases. The large velocity generates the fast increase in total pressure loss, mainly because increasing inlet velocity makes the flow field in combustor more chaotic, and the flow resistance increases obviously. Similarly, too little inlet velocity may cause combustion instability, so when choosing appropriate inlet velocity, total pressure loss can only be regarded as one of the criteria, and other criteria factors need to be taken into account. But from $V=10 \mathrm{~m} / \mathrm{s}$ to $V=110 \mathrm{~m} / \mathrm{s}$, combustion efficiency is relatively stable, which indicates that inlet flow velocity has little effect on combustion efficiency.

Figure 26 shows the synergy angle distribution at different section and different inlet velocities and distributions of different inlet velocities with small synergy-region angles in the cavity, behind the guide vane and inclined struts, and behind the blunt body. Because different inlet velocities have different flow fields, which can affect the combustion, the temperature is varied. And the combustion influences the flow field in turn. These factors make the angle between the velocity vector and the temperature gradient change.

Figure 27 reveals the change of the volume average synergy angle and the area average synergy angle at section $Z=0 \mathrm{~mm}$ with inlet velocities differently. When inlet velocity increases, its volume average synergy angle and the area average synergy angle increase first and then tend to be stable. When $V<50 \mathrm{~m} / \mathrm{s}$, there are rapid increases in the field average synergy angle as inlet velocity increases. When the velocity is more than $50 \mathrm{~m} / \mathrm{s}$, the change of field average synergy angle is small. This shows that the lower flow velocity makes the field synergy better.

4.2.3. Effect of Inlet Temperature on the Characteristics of $A V C$. Figure 28 shows relatively stable vortex, which is behind guide vane and near front wall of the cavity. As inlet temperature increases, velocity behind blunt body decreases, and backflow behind elongates. To a great degree, as inlet temperature increases within the region of cavity and backflow of the blunt body, their temperatures increase obviously, and the larger gas viscosity decreases the flow velocity in the rear part of the combustor and elongates the length of the low velocity backflow region.
As can be seen from Figure 29, higher inlet temperature can effectively accelerate the chemical reaction rate, and the heat release from combustion can increase the overall temperature and shorten the mainstream low temperature zone. But the overall temperature rise is almost the same, which is about $1550 \mathrm{~K}$. The high inlet temperature has tiny effect on rise of the maximum temperature. When inlet temperature increases behind the blunt body, temperature and gas viscosity increase, but the velocity slows down, which results in the decrease of the turbulent kinetic energy, but in the blunt body, regional length of backflow behind it is elongated as the gas viscosity increases, and the region with strong heat and mass transfer capacity becomes larger.

From Figure 30, total pressure loss decreases gradually when inlet temperature increases. The larger the temperature rise, the greater the heat resistance in the direction of heat transfer, and the greater total pressure loss. However, when inlet temperature changes, combustion efficiency does not change nearly.

Figure 31 shows the synergy angle distribution at different section and different inlet temperatures. According to Figure 32, when inlet temperature increases, area synergy angle in average at section $Z=0 \mathrm{~mm}$ decreases. When inlet temperature is $700 \mathrm{~K}$, the area average synergy angle drops fast. But the volume average synergy angle does not change much, and the increase of inlet temperature does not better integrate field of velocity and temperature in the combustor. The reason (combined with Figure 31) is when inlet temperature increases, at section $Z=0 \mathrm{~mm}$, in the blunt body, the areal synergy angle of backflow with low velocity decreases, and area average synergy angle decreases gradually. However, at section $Z=7 \mathrm{~mm}$, the large inlet temperature generates greater synergy angle of backflow with low velocity, and volume average synergy angle does not change much. The results show when inlet temperature increases, field synergy angle in average in $-7 \mathrm{~mm}<Z<7 \mathrm{~mm}$ decreases and the heat transfer ability enhances, but the field average synergy angle in $Z<-7 \mathrm{~mm}$ and $Z>7 \mathrm{~mm}$ increases. There is no obvious variation in the overall heat transfer capacity. In addition, Figure 32 shows that volume average synergy angle is obviously larger than the area average synergy angle.

\section{Conclusions}

This paper studied the effect of structural parameters on combustion flow for improving TVC performances. Besides, how different inlets affect TVC combustion flow features in light of optimal structure is studied.

(1) When there are obstacles including blunt body, inclined struts, and guide vane, structures based on stable double vortices can be formed, which is beneficial to steady combustion and gas mixing. Compared with the case of only blunt body, combustion efficiency of the combustor can be greatly improved

(2) The optimum structural parameters of the inclined struts are $\alpha=30^{\circ}$ and $\mathrm{BR}=12 \%$; the guide vane and its optimum structural parameters are as 
follows: $a / B=0.1, \quad b / h=0.4$, and $c / L=0.2$; the blunt body has an optimal height of $H_{1} / B_{1}=2 / 3$

(3) The inlet cavity after the guide vane, blunt body, and inclined struts are distribution regions of small synergy angles; this means the trapped vortex region and the low velocity backflow region have good field synergy. As inlet velocity increases, the flow resistance increases. As inlet temperature increases, the flow resistance decreases. From field synergy theory, inlet factors have different effect on the heat transfer performance

\section{Data Availability}

The data of this study is available from Capacity Building Projects in Local Universities of Science and Technology Commission of Shanghai Municipality (19020500900).

\section{Conflicts of Interest}

We declare that we have no financial and personal relationships with other people or organizations that can inappropriately influence our work; there is no professional or other personal interest of any nature or kind in any product, service, and/or company that could be construed as influencing the position presented in or the review of the manuscript entitled "Combustion turbulence flow in the advanced vortex combustor with built-in obstacles."

\section{References}

[1] K. Y. Hsu, L. P. Goss, and D. D. Trump, "Performance of a trapped-vortex combustor," in 33rd Aerospace Sciences Meeting and Exhibit, Reno, NV, U. S. A., 1995.

[2] G. Chaouki, Z. Khaled, and J. Isam, "Combustion of alternative fuels in vortex trapped combustor," Energy Conversion and Management, vol. 65, pp. 819-828, 2013.

[3] S. Krishna and R. V. Ravikrishna, "Optical diagnostics of fuelair mixing and vortex formation in a cavity combustor," Experimental Thermal and Fluid Science, vol. 61, pp. 163176, 2015.

[4] Z. X. Zeng, H. Y. Wang, and Z. K. Wang, "Analysis of cooling performance and combustion flow in advanced vortex combustor with guide vane," Aerospace Science and Technology, vol. 72, pp. 542-552, 2018.

[5] Z. X. Zeng, K. F. Guo, and X. Gong, "Combustion turbulence flow in trapped vortex combustor with guide vane and blunt body," International Journal of Aerospace Engineering, vol. 2020, Article ID 8882343, 19 pages, 2020.

[6] P. Jiang and X. M. He, "Ignition characteristics of a novel mixed-flow trapped vortex combustor for turboshaft engine," Fuel, vol. 261, article 116430, 2020.

[7] Z. J. Wu and X. M. He, "Investigations on emission characteristics of a liquid-fueled trapped vortex combustor," Journal of Thermal Science, vol. 29, no. 1, pp. 69-80, 2020.

[8] R. G. Edmonds, J. T. Williams, R. C. Steele, D. L. Straub, K. H. Casleton, and A. Bining, "Low NOx advanced vortex combustor," Journal of Engineering for Gas Turbines and Power, vol. 130, no. 3, article 034502, 2008.

[9] Y. B. Deng, L. H. Zheng, F. M. Su, and C. Ma, "Flow and combustion characteristics of annular advanced vortex combus- tor," in ASME 2017 International Mechanical Engineering Congress and Exposition, Phoenix, AZ, US, 2016.

[10] Z. X. Zeng, P. du, Z. K. Wang, and K. Li, "Combustion flow in different advanced vortex combustors with/without vortex generator," Aerospace Science and Technology, vol. 86, pp. 640-649, 2019.

[11] Z. X. Zeng, H. Cheng, and Z. K. Wang, "Investigation of the flow and heat transfer characteristics in advanced vortex combustor," International Journal of Thermal Sciences, vol. 156, article 106459, 2020.

[12] J. Xie and Y. J. Zhu, "Characteristics study on a modified advanced vortex combustor," Energy, vol. 193, article 116805, 2020.

[13] C. T. Zhang and J. Y. Liu, Investigations of flow guide vanes geometric parameters on performance of four-duct-annular advanced vortex combustor, Advances in Aeronautical Science and Engineering, 2021.

[14] K. K. Agarwal and R. V. Ravikrishna, "Experimental and numerical studies in a compact trapped vortex combustor: stability assessment and augmentation," Combustion Science and Technology, vol. 183, no. 12, pp. 1308-1327, 2011.

[15] K. K. Agarwal, S. Krishna, and R. V. Ravikrishna, "Mixing enhancement in a compact trapped vortex combustor," Combustion Science and Technology, vol. 185, no. 3, pp. 363-378, 2013.

[16] T. H. Shih, W. W. Liou, A. Shabbir, Z. Yang, and J. Zhu, "A new $k$ - $\epsilon$ eddy viscosity model for high Reynolds number turbulent flows," Computers \& Fluids, vol. 24, no. 3, pp. 227238, 1995 .

[17] B. F. Magnussen and B. H. Hjertager, "On mathematical modeling of turbulent combustion with special emphasis on soot formation and combustion," Symposium on Combustion, vol. 16, no. 1, pp. 719-729, 1977.

[18] D. B. Spalding, "Numerical Computation of Multiphase Fluid Flow and Heat Transfer," in Recent Advances in Numerical Methods in Fluids, vol. 1, pp. 139-167, Pineridge Press Limited, Swansea, UK, 1980.

[19] X. M. He and J. H. Wang, "An investigation on the fluid characteristics of trapped-vortex combustor," Journal of Aerospace Power, vol. 17, no. 5, pp. 567-571, 2002.

[20] S. Q. Liu and J. J. Zhong, "Vortex system distribution in a vortex combustion chamber," Journal of Dalian Maritime University, vol. 35, no. 4, pp. 103-107,112, 2009.

[21] F. C. Zhuang and L. S. Zhong, "A simplified model for combustor design of spontaneous propellant liquid rocket engine," Chinese Journal of Engineering Science, vol. 4, pp. 4-37, 1979.

[22] Z. Y. Guo, "Principle of field coordination in heat exchangers and its applications," Chinese Journal of Mechanical Engineering, vol. 39, no. 12, pp. 1-9, 2003.

[23] W. Q. Tao, Y. L. He, Q. W. Wang, Z. G. Qu, and F. Q. Song, “A unified analysis on enhancing single phase convective heat transfer with field synergy principle," International Journal of Heat and Mass Transfer, vol. 45, no. 24, pp. 4871-4879, 2002.

[24] J. A. Men, X. G. Liang, and Z. X. Li, "Field synergy optimization and enhanced heat transfer by multi-longitudinal vortexes flow in tube," International Journal of Heat and Mass Transfer, vol. 48, no. 16, pp. 3331-3337, 2005.

[25] Z. Guo and S. Huang, Field Synergy Principle and New Technology of Heat Transfer Enhancement, China Electric Power Press, 2004. 